\title{
Integrating Time-Limited Dynamic Psychotherapy and a Buddhism-Inspired Aversion/Attachment Model of Client Suffering: The Cases of "Beth" and "Amy"
}

\author{
JASON SAMLIN a,b,c \\ ${ }^{\text {a }}$ Commonwealth Psychology Associates, Newton, MA \\ b Correspondence regarding this article should be sent to Jason Samlin, Commonwealth Psychology Associates, 2 \\ Executive Park Drive, Suite 200, Newton, MA 02462 \\ Email: jmsamlin@gmail.com \\ c Note: This article is a reformatted and edited version of my dissertation (Samlin, 2015).
}

\begin{abstract}
In recent times, Buddhist psychological concepts have become appealing to many psychotherapy theorists and practitioners. Included are such notions as mindfulness, the "acceptance" of experience, the nature and causes of suffering, and the use of "skillful means" behaviors and thoughts that are intentionally undertaken to reduce suffering both for oneself and others. While there are a number of cognitive-behavioral therapy treatments that incorporate such Buddhist psychological concepts, little research and practice has been done examining the integration of such concepts and short-term dynamic psychotherapy. As one effort to fill this gap in research, the purpose of this study was to develop and pilot test in two cases_-Beth" and "Amy"—a model (a) that was based on such Buddhist concepts and (b) that would assimilatively integrate with the "home theory" of an established form of modern, relational, short-term psychodynamic psychotherapy, namely, Levenson's (1995, 2010) Time-Limited Dynamic Psychotherapy (TLDP). The new model is called the "Aversion/Attachment Model of Client Suffering" (A/AMCS). The A/AMCS model was conceptually incorporated into Beth's and Amy's case formulations through an expansion of TLDP's case formulation method. Also, the A/AMCS model was technically integrated into TLDP treatment in two ways. First, formal mindfulness meditation practices were implemented with each client by conducting eight half-hour practices before sessions 6-13, in the context of therapy that lasted 23 and 20 sessions, respectively. Second, the treatment sessions included the incorporation of acceptance practices and skillful means strategies. Following the Pragmatic Case Study Method (Fishman, 2005), Beth and Amy's cases are examined both quantitatively and qualitatively. This study concludes with a discussion of the possible reasons for Beth's dramatically positive outcome compared with Amy's only moderately successful outcome, together with a broader discussion of how future research could further examine the integration of Buddhist psychological concepts and shortterm psychodynamic psychotherapy.
\end{abstract}

Key words: Time-Limited Dynamic Psychotherapy (TLDP); Cyclical Maladaptive Pattern (CMP); Buddhist psychological concepts; an Aversion/Attachment Model of Client Suffering (A/AMCS); mindfulness; depression; anxiety; case studies; clinical case studies 
Pragmatic Case Studies in Psychotherapy, http://pcsp.libraries.rutgers.edu

Volume 12, Module 4, Article 1, pp. 238-308, 12-16-16 [copyright by author]

\section{CASE CONTEXT AND METHOD}

\section{Rationale for Selecting These Two Clients for Study}

The intersection of psychology and Buddhism has deep roots, as reflected in the work of both William James and Carl Jung (Epstein, 1995, Fields, 1981). In the mid-twentieth century, psychoanalytic theorists such as Karen Horney and Erich Fromm examined how the Zen Buddhist concepts like the "true self" and "Buddha nature" compared to the concept of the ego in psychoanalysis (DeMartino, 1991; Fromm, Suzuki, \& DeMartino, 1960) More recently, cognitive-behavioral therapy has begun to incorporate elements of Buddhist psychology into treatments such as Dialectical Behavior Therapy (Linnehan, 1993) and Acceptance and Commitment Therapy (Hayes, Strosahl, \& Wilson, 2011). Within the last fifteen years, there has also been a significant increase in the scholarly examination of mindfulness and Buddhist psychology in the frame of western psychological thought: while there were only 21 studies pertaining to mindfulness and Buddhist psychology in 2000, there were 477 articles on this topic published in 2013 (Black, 2014). Technical material is also now available on theory-neutral methods of incorporating mindfulness practice and concepts into psychotherapy (Hick \& Bien, 2008; Pollack, Pedulla, \& Siegal, 2014).

While psychoanalytic and psychodynamic therapy has a great deal of literature on the integration of Buddhism and psychoanalytic theory (Safran, 2003), there is comparatively little recent literature on the use of Buddhist psychology in psychotherapy. What literature there is focuses either on particular Buddhist psychological concepts, such as mindfulness and acceptance within the context of the therapy relationship (Safran \& Muran, 2000), or the integration of Buddhist psychology into long-term, open-ended treatment (Epstein, 1995, 2008). Furthermore, the literature on Buddhist psychology and long-term therapy is anecdotal and, while interesting, is not systematic and concrete enough to be able to draw practical conclusions. This lack of scholarship on the integration of Buddhist psychology and psychodynamic psychotherapy represents a large gap in the literature and an area where psychodynamic therapy is trailing behind cognitive behavior therapy.

It is this gap in the integration of Buddhist psychology concepts and psychodynamic psychotherapy that this study is designed to fill. The study will examine the integration of a specific Buddhist psychological concepts with a type of short-term dynamic therapy, TimeLimited Dynamic Psychotherapy (TLDP). TLDP was chosen because it is representative of the modern, relational short-term dynamic psychotherapies that are currently practiced (Levenson, 2010).

With this purpose in mind, clients were selected based on their appropriateness for an experimental treatment that incorporates the explicit practice of mindfulness meditation. Given that this treatment would be short-term in nature, Levenson's (1995) inclusion/exclusion criteria were used to determine a potential participant's general appropriateness for the study. Appropriate clients would be willing to engage in meditation practice, complete assigned homework, and present with problems that could be reasonably addressed in a short-term format. 
Given that this study is exploratory, there were few restrictions in regards to a client's presenting problem, though individuals with active psychosis were excluded from the study.

The two clients, "Beth” and “Amy,” were selected for treatment because they communicated willingness to be involved in an experimental treatment and engage in mindfulness practice, though neither had heard of mindfulness meditation prior to treatment. Additionally, both clients met the inclusion criteria outlined in Table 1.

\section{Clinical Setting in Which the Cases Took Place}

The treatments of Beth and Amy took place in a University-run community outpatient clinic in the northeastern United States. Each client paid for treatment on a sliding fee scale, according to her income. At the time of treatment, I was an advanced doctoral student in clinical psychology.

Both Beth and Amy were referred to me by the clinic coordinators of the outpatient clinic and completed two intake sessions prior to entering the study and beginning treatment. The clients were informed at the beginning of treatment of the short-term nature of the treatment and consented to such treatment. Treatment was scheduled to last between 5-6 months for each client; Beth completed 23 sessions of treatment, and Amy completed 20.

\section{Methodological Strategies Employed for Enhancing the Rigor of the Study}

The case was supervised by Dr. Seth Warren, a senior psychodynamically oriented therapist with a background in Buddhist psychological concepts and mindfulness meditation. All sessions were DVD recorded and reviewed by me and by Dr. Warren, as part of the supervision. I met weekly with Dr. Warren and supervision was concerned with determining both (a) how the clients' presenting problems were being addressed within the short-term psychodynamic model employed, and (b) how I might more effectively tailor the contributions of Buddhist psychology to the particulars of the given case.

The clients also completed seven standardized, quantitative measures at the beginning and end of therapy, with up to four of these measures completed every session. A more detailed description of these measures is presented in the Assessment sections below.

\section{Sources of Data Available Concerning the Clients}

Prior to the first intake session, I was provided with a very brief face sheet for each client that was completed by the clinic coordinators following a 15-minute phone triage with the client. No other information was provided to me before the intake sessions.

\section{Confidentiality}

Confidentiality is maintained by including no identifying information in this write-up. I have attempted to maintain as much clinical authenticity as possible, but some details of the case have been disguised in order to further decrease the likelihood of identification. 
Pragmatic Case Studies in Psychotherapy, http://pcsp.libraries.rutgers.edu

Volume 12, Module 4, Article 1, pp. 238-308, 12-16-16 [copyright by author]

\section{THE CLIENTS}

"Beth,” a 21-year-old Latina and recent college graduate, sought treatment in order to address symptoms of depression, low self-worth, passive suicidal ideation, intermittent selfinjurious behavior, and periods of acute dysphoria and self-hatred. She presented with symptoms of a DSM-5 diagnosis of Major Depressive Episode, including depressed mood for most of the day nearly every day, fatigue, anhedonia, passive suicidality, concentration difficulties, feelings of worthlessness, and decreased appetite. Beth had experienced four recurrent episodes of Major Depression since she was twelve years old, with the depressive episodes lasting between three months and a year, and thus her Major Depressive Episode was categorized as Recurrent Type. Beth also had been diagnosed and treated for Bulimia Nervosa, Non-Purging Type in the past, but did not present to treatment with any symptoms of this diagnosis, although she did have a negative opinion of her body. Prior to our work together, Beth had been in individual psychotherapy treatment three times since the age of twelve: she was in treatment twice while in middle school, which she reported were unsuccessful, and once for two years while in college, in which she was treated successfully for her eating disorder behavior. At the time of treatment, Beth was working part-time in a day care agency and living with her boyfriend of two years, whom she considered a support in her life. Beth was a likable, personable woman and appeared comfortable talking about her history of psychological distress and treatment.

“Amy,” a 25-year old Caucasian female, presented for treatment in order to improve her communication with her father, brother, and boyfriend, and to develop stress management strategies. She presented with several symptoms indicative of an anxiety disorder, including rumination, anxiety and trouble concentrating when speaking to her father and brother, anticipatory anxiety, and muscle soreness after worrying. Although Amy exhibited symptoms of a DSM-5 diagnosis of Generalized Anxiety Disorder, her anxiety was limited to situations in which she interacted with her father or brother and to situations where she felt she was causing someone disappointment; and thus she was given the diagnosis of Anxiety Disorder Not Otherwise Specified. Amy's anxiety, as well as the typical triggers for her anxiety, began in middle school and had continued until she presented for treatment. Prior to our treatment, Amy attended five sessions of a women's support group while in college, but never received individual psychotherapy. At the time of treatment Amy was living with her parents and one older brother and worked as an office assistant. While Amy was a personable woman, when beginning treatment she presented a combination of both exhibiting anxiety symptoms and at the same time verbally minimizing them.

\section{GUIDING CONCEPTION, WITH RESEARCH AND CLINICAL EXPERIENCE SUPPORT}

\section{Time Limited Dynamic Psychotherapy (TLDP)}

Time-Limited Dynamic Psychotherapy was originally created by Binder \& Strupp (1991) and further refined by Levenson $(1995,2010)$. The type of TLDP that will be utilized in the case studies is the most recent version of Levenson's (2010) treatment. TLDP is situated in the 
relational school of psychoanalysis (Messer \& Warren, 1995) and is considered a part of the “fourth generation” of time-limited psychodynamic treatments (Levenson, 2010).

TLDP is informed by three psychological theories: (a) attachment theory, which is based on the work by Bowlby $(1969,1973,1980)$ and Ainsworth $(1969,1989)$; (b) interpersonalrelational theory, first elucidated by Harry Stack Sullivan (1953) and later refined by theorists such as Benjamin $(1974,1993)$; and (c) experiential-affective theory, which forms the basis of therapies such as Emotion-Focused Therapy (Greenberg, 2002) and Accelerated-Experiential Dynamic Psychotherapy (Fosha, 2000). Against the backdrop of these three foundational theories, TLDP has nine central principles that undergird conceptualization and treatment (see Levenson, 2010, pp. 45-55).

1. People are innately motivated to search for and maintain human relatedness.

2. Maladaptive relational patterns are acquired early in life, become schematized, and underlie many presenting complaints.

3. Relational patterns persist because they are maintained in current relationships and are consistent with the person's sense of self and other.

4. Therefore in TLDP, clients are viewed as stuck, not sick.

5. The focus in TLDP is on shifting maladaptive relationship patterns and their attendant emotions.

6. TLDP is concerned with interactive interpersonal processes rather than specific content.

7. TLDP focuses on one chief problematic relationship pattern (called the Cyclical Maladaptive Pattern, or CMP).

8. The therapist is both a participant and an observer in treatment.

9. The change process will continue after the therapy is terminated.

\section{Case Formulation in TLDP: The Cyclical Maladaptive Pattern}

Case formulation in TLDP centers on conceptualizing a Cyclical Maladaptive Pattern (CMP) that explains the client's core, dysfunctional interpersonal interactions. The CMP describes cycles of rigid, self-defeating, and self-perpetuating behaviors that lead to maladaptive interpersonal interactions with others (Butler, Strupp, \& Binder, 1993). Importantly, the CMP is not considered a complete truth of the client's behavior, but rather a "plausible narrative" (Levenson, 2010, p. 68) of how the client's history and current functioning impact the target maladaptive interpersonal pattern. Levenson (2010, p. 68) explains that the CMP could be thought of as "a fluid, individualistic, working formulation that is meant to be refined throughout therapy."

A CMP formulation consists of five sections: (a) Acts of the Self, which include feelings, thoughts, motives, and perceptions that are interpersonal in nature; (b) Expectations of Others' Reactions, which comprises the client's thoughts and feelings related to how the client imagines others will react to him or her; (c) Acts of Others Toward the Self, which consists of the behaviors of others as directly experienced, or assumed, and interpreted by the client, frequently 
with an explanation for the others' actions; (d) Acts of the Self Toward the Self, which is comprised of the client's thoughts, feelings, and behaviors towards his or herself, highlighting the client's introjects (images of others that have been internalized) and the client's perception of his or herself; and (e) Therapist's Interactive Countertransference, which is made up of the therapist's cognitive, affective, and behavioral reactions to the client that are primarily shaped and evoked by the client's interactive patterns. Once the CMP is complete for the client, the following cyclical narrative can be explained:

The client behaves, feels, and thinks in certain ways regarding transactions with others and has come to expect others to behave in certain ways in response. These expectations are communicated to others primarily through nonverbal, emotional signals that trigger others to behave in ways the client unconsciously expects. The client then reads these complementary behaviors also through an emotional lens, and these apperceptions affect the client's selfappraisal and treatment of himself or herself, which further encourages the client to behave, feel, and think is certain ways, completing the cycle. (Levenson, 2010, p. 75).

\section{Goals and Interventions in TDLP}

There are two main goals in TLDP: providing new emotional experiences for the client and providing new understanding for the client. Clients achieve these goals both interpersonally, and intrapersonally. The therapist attempts to give clients new interpersonal experiences by encouraging the client to take risks in the face of anxiety and responding differently than what the client feared. Over time, through the client experiencing interpersonal interactions, both in and outside of treatment, that disconfirm entrenched interpersonal assumptions and beliefs, the client's dysfunctional interpersonal style is reconfigured and more adaptive interpersonal behaviors can be learned (Levenson, 2010). Intrapersonally, TLDP attempts to shift the client's internal emotional experience. This is accomplished through the therapist's regulationfacilitating, accepting presence and the client's experience of positive emotion. By providing a validating, welcoming environment in which the client is situated, the therapist can aid the client in experiencing previously unacceptable or scary emotional states. In this way, the therapist is helping the client alter maladaptive emotional states through the experiencing of more adaptive emotions (Greenberg \& Pascual-Leone, 2006).

Providing new understanding for the client, in addition to new experiences, is important because it allows the client to "reflect and make meaning” (Levenson, 2010, p. 61) of relational and emotional experiences. Interpersonally, the therapist attempts to aid the client in understanding the client's maladaptive relational patterns. The focus here is identifying the reasons why the maladaptive patterns occurred and how they are maintained. Intrapersonally, the therapist encourages the client to develop new understanding by bringing awareness to, and reflecting on, what is occurring in the therapy in the present moment; the focus is around why the client is re-enacting maladaptive relational patterns with the therapist. During this process, the client is encouraged to bring a non-judgmental curiosity to new information, and the therapist tries to prevent the client from self-blaming for maladaptive patterns. By focusing on fostering both new experience and new understanding, the TLDP clinician is attempting to give the client an understanding of why his or her maladaptive relational patterns are occurring and the new experience necessary to break those patterns. 
Pragmatic Case Studies in Psychotherapy, http://pcsp.libraries.rutgers.edu

Volume 12, Module 4, Article 1, pp. 238-308, 12-16-16 [copyright by author]

Levenson (2010) describes 25 intervention strategies that can be used in the context of TLDP. Each intervention is designed to further the client's understanding and experience of themselves as a part of relationships (for details about the strategies, see Levenson, 2010, pp. 8194). It is important to note that, while Levenson has outlined 25 discrete intervention strategies, she makes a point of expressing that any intervention designed in line with TLDP's goals could be considered an appropriate intervention in the context of treatment. for example, Levenson explains that she has used interventions from various traditions, such as the Gestalt empty-chair technique and behavioral rehearsal/homework with clients when such interventions have served the purpose of advancing the client's experience or understanding of themselves and their relationships (Levenson, 2010). While interventions in TLDP can be seen as pragmatic in the sense of ultimately serving the overarching goals of treatment, Levenson echoes Messer's (1992) caution to be mindful of how an intervention's effect might change when taken out of its original theory and context.

\section{$\underline{\text { Empirical Support for TLDP }}$}

While the effectiveness of TLDP itself has not been examined in a controlled experimental setting, studies have suggested that TLDP treatment can produce client change that is associated with positive treatment outcomes. Harris, Quintana, Strupp, and Henry (1994) found that TLDP encourages the client to internalize positive aspects of the therapist-client dyad, which was associated with positive outcomes on measures of depression and anxiety. Additionally, Travis, Binder, Bliwise, and Horne-Moyer (2001) examined the change in attachment style of clients who underwent a course of TLDP treatment. The researchers found that a significant portion of clients shifted attachment styles from less adaptive insecure to more adaptive secure styles over the course of therapy, which is consistent with TLDP's focus on altering maladaptive attachment styles.

Short-Term Dynamic Psychotherapy, a broad category of therapy treatments which includes TLPD, has a much broader base of empirical support for a wide variety of psychological difficulties. Driessen, Cuijpers, de Maat, Abbass, de Jonghe, and Dekker (2010) conducted a meta-analysis of 23 studies examining the effect of short-term psychodynamic psychotherapy on depression and concluded that short-term psychodynamic treatment is an effective treatment for depression, with a large effect size $(\mathrm{d}=1.34)$ found between pre- and post-treatment measures of depression. Abbass, Kisley, and Kroenke (2009) examined the effects of short-term dynamic psychotherapy for a wide array of somatic conditions and found post-treatment improvement in both general psychological functioning and somatic distress (effect sizes of .69 and .59 respectively).

Perhaps reflective of this research, there are three types of psychodynamic psychotherapy that are categorized as Research-Supported Psychological Treatments (Society of Clinical Psychology, 2014). Two short-term treatments are listed, Psychoanalytic Therapy for Panic Disorder and Short-Term Psychodynamic Psychotherapy for Depression, while one treatment is long-term, Transference-Focused Psychotherapy for Borderline Personality Disorder. 
Pragmatic Case Studies in Psychotherapy, http://pcsp.libraries.rutgers.edu

Volume 12, Module 4, Article 1, pp. 238-308, 12-16-16 [copyright by author]

\section{The Attachment/Aversion Model of Client Suffering (A/AMCS)}

The A/AMCS was created specifically for this study as a way to more systematically and operationally translate some of the practices and concepts in Buddhist psychology into a form that could be integrated into short-term dynamic therapy, particularly those that have been successfully adapted to other types of therapy, like mindfulness and acceptance. It should be noted that A/AMCS is not designed to be a complete, exhaustive integration of Buddhist concepts and modern western psychology, and that this is still a rich area to be further mined.

The Buddhist tradition from which the A/AMCS draws most heavily has become known as the Vipassana Movement in western cultures (Frondsal, 1998). The Vipassana movement draws most from the Thai Forest tradition of Theravada Buddhism, but also incorporates teachers and teachings from other traditions such a Zen and Tibetan Buddhism (Frondsal, 1998). It is part of a larger movement of Buddhist modernism that draws most from texts immediately after the time of the Buddha and is generally secular in nature. Rather than emphasizing ritual and dogma, the Vipassana movement puts more of an emphasis on direct practice and pragmatic teachings (McMahan, 2008). I chose the modern Vipassana Movement as the base for the A/AMCS because of its focus on secular teaching, because of its use in other psychotherapies, and my own positive personal experience of practicing mindfulness meditation within the Vipassana movement.

\section{Suffering, Attachment, Aversion, and Psychopathology in the A/AMCS}

Rather than orient to discrete diagnoses and psychopathology, the A/AMCS focuses instead upon the concept of psychological "suffering." This focus on suffering is drawn directly from Buddhist psychology, which concerns itself exclusively with the causes and alleviation of suffering (Olendzki, 2003). Suffering can be defined as the "inevitable unsatisfactoriness of human experience” (Olendzki, 2010) and is experienced, in at least some capacity, by every living being. The Buddha addresses this at the beginning of all his teachings in the First Noble Truth when he declares that suffering is present and inevitable in the world (Olendzki, 2003). The A/AMCS, then, takes as the focus of clinical interest the ways in which the client's thoughts and behaviors cause further suffering and aims to aid the client in developing the capacity to reduce this suffering.

An important notion in the A/AMCS model is the Buddhist concept of "attachment." Whereas in Western psychology attachment is typically used in regards to an individual's orientation to others, in Buddhist psychology and the A/AMCS model attachment refers exclusively to internal experiences and feeling states (Cullen, 2011); an individual never desires or clings to material goods or objects, but to the feeling states that those material objects engender. In this context, one root cause of suffering is the process of futilely "trying to hold on to the stability of a passing moment, feeling, or relationship" while struggling "against the impermanence of all phenomena” (Kumar, 2002, pp. 41-42).

In line with the above, in the A/AMCS, one focus of a case formulation is on the client's internal states. The therapist answers questions such as: What internal experience is the client trying to prolong or maintain? How is the client trying to pursue or maintain this experience? 
and, How is the client's attachment behavior causing problems or impairment in his or her life? Through answering these questions, the therapist can not only begin to formulate the process by which the client attempts to maintain pleasurable internal states, but also begin to identify in what way this behavior is causing the client distress and impairment. For example, a client may be very shy and conciliatory in relationships, leading to the client rarely getting his interpersonal needs met. The abovementioned questions would examine what states the client achieves by acting in a conciliatory manner (he may, for example, feel comforted and taken care of by having another "take charge" in interpersonal situations), and how the behavior he engages in to achieve these internal states causes difficulties.

As the name of this model suggests, the A/AMCS concerns itself with the ways in which both attachment and aversion influence client suffering. Aversion is a process by which an individual attempts to avoid internal states and experiences that are unpleasant. Unpleasant internal states, though, are inevitable in life, and suffering can occur when individuals attempt to avoid unavoidable unpleasant experience. "Turning away" from this unpleasant experience moves one away from present experience and prevents one from engaging in what is actually happening in the present moment (Goldstein, 2010). For example, if an individual is attempting to avoid relationship conflict with his or her partner because he or she feels like they "ruin" the relationship whenever there is conflict, the individual will be unable to address any feelings of relationship frustration or anger that he or she may actually be experiencing; this individual is prevented from attending and addressing real internal states of frustration and anger because he or she is turning away from the fear that they might ruin the relationship through conflict.

Aversion and its contribution to suffering, viewed in this context, is similar to the behavioral concept of "experiential avoidance" (Hayes, Wilson, Gifford, Follette, \& Strosahl, 1996). In both of these constructs, individuals are caused further psychological discomfort and suffering through their avoidance of aversive internal states and, because of this avoidance, they are unable to address these unpleasant internal states.

The client's pattern of attachment and aversion interact to prevent the client from effectively interacting with his or her experience. Both aversive and attachment tendencies contribute to the client behaving in a reactive manner that, ultimately, increases suffering. This reactive suffering is best described through the Buddhist concept of the "second dart" (Feldman \& Kuyken, 2011; Kabat-Zinn, 1990). In this conceptualization of suffering, one's raw experience (for example, grief after a loss, anxiety while taking a test) is considered the "first dart," which does not, in and of itself, create additional suffering. One's unskillful reactions to experience (for example, "I shouldn't feel this way," "I need to keep feeling this way") constitute the second dart, which is the root cause of psychological distress and suffering.

In order to effectively understand the causes and effects of the client's suffering, the therapist must create a working model of: (a) what internal states are being avoided or clung to, (b) in what behavior is the client engaging that facilitates this avoidance or clinging, and (c) how this behavior is causing the client distress and/or impairment. When these three components of the client's experience of suffering are properly elucidated, the therapist will then have the 
Pragmatic Case Studies in Psychotherapy, http://pcsp.libraries.rutgers.edu

Volume 12, Module 4, Article 1, pp. 238-308, 12-16-16 [copyright by author]

information needed to determine where and how best to intervene and interrupt the cycle of maladaptive avoidance and attachment.

\section{Intervention Strategies in the A/AMCS}

The point of intervention within the A/AMCS is, predominantly, the thoughts and behaviors that constitute the second dart for the client; treatment strategies address the ways in which a client is disengaging with the present moment. There are four broad intervention strategies that can be used within the A/AMCS to address client suffering: mindfulness meditation, "turning toward" one's experiences, and "skillful means."

Meditation. The first intervention strategy is mindfulness meditation. For the purposes of this study, I've chosen to combine both Germer's (2013) and Kabat-Zinn's (2003) definitions and define mindfulness as: the awareness of present experience that emerges through paying attention on purpose, and with acceptance. Pollack, Pedulla, and Siegal (2014) describe three levels of mindfulness in psychotherapy, ranging from implicit to explicit use of mindfulness: (a) a meditation-practicing therapist relating to the client mindfully; (b) using insights into the nature of suffering gained through mindfulness practice with clients; and (c) explicitly teaching mindfulness meditation to clients.

As the therapist in Beth's and Amy's cases, I employed all three of these levels of mindfulness into treatment. In addition to my practicing mindfulness meditation and bringing a mindful presence to the therapy dyad, I explored with the clients how operating on "automatic pilot," away from the present moment, was increasing suffering. I also instructed Beth and Amy in formal meditation practice modeled after the eight-week programs of Mindfulness-Based Stress Reduction (MBSR; Kabat-Zinn, 1990) and Mindfulness-Based Cognitive Therapy (MBCT; Segal, Williams, \& Teasdale, 2012). The insights and processes of the formal practice sessions were then referenced and alluded to during the formal therapy sessions to reinforce the clients' understanding and experience of mindfulness.

Mindfulness is a primary treatment method within the A/AMCS for a number of reasons. First, in Buddhism mindfulness meditation has been practiced as a means to reduce suffering for centuries and is thought of as one of the eight primary ways the Buddha identified in which an individual can achieve freedom from suffering (Olendzki, 2005). Pragmatically, mindfulness meditation is utilized in order to identify and slow down the automatic processes of attachment and aversion which contribute to suffering. Mindfulness meditation allows the client to slow down and bring awareness to that nature of the attachment or aversion that is contributing to the client's suffering. Engaging in mindfulness meditation provides the client with the direct experience of witnessing the nature of his or her suffering as it is occurring in the moment, allowing the client to develop the capacity to make space for his or her suffering.

"Turning Towards" one's experiences. The second intervention strategy, which is intertwined in treatment with the practice of mindfulness, consists of the process of "Turning Towards" one's experiences (Cullen. 2011; Santorelli, 1999). Rather than a discrete intervention, Turning Towards suffering involves a constant process of noticing what internal states are being avoided or changed and bringing attention to those states. This could occur through the therapist 
bringing attention back to internal experiences that are being avoided or, if the client has cultivated this ability, the client actively exploring aversive states. Whereas mindfulness practice aids the client in noticing aversive states and the avoidance of those aversive states, the process of Turning Towards actively engages the client in an exploration and processing of those aversive states.

The Turning Towards process is similar to exposure therapy in that both involve the client sitting and skillfully interacting with aversive experience (Fulton \& Siegel, 2005). Just as in exposure therapy, the client should not engage in Turning Towards without tools to be able to effectively deal with aversive experience. Where exposure therapy aids the client in this process through techniques like progressive muscle relaxation and moving through hierarchies of exposure situations, in the A/AMCS model the therapist aids the client in Turning Towards through the cultivation of self-compassion, patience, and acceptance of their experience (Baraz, 2009).

When a client has begun cultivating the ability to sit with and bring awareness to the ways in which they move away from present experience in order to avoid unpleasant or dissatisfactory states, the client is freed to choose how to respond, rather than react, to their experience (Coleman, 2013; Rothberg, 2014).

"Skillful Means." The final process through which the therapist aids the client in reducing suffering is through the cultivation of skillful responses to experience. The term skillful in this context is taken from the Buddhist concept of Skillful Means, which originally referred to the Buddha's ability to convey his teachings at the level of the listener (Pye, 2003). More recently, the concept has referred to behaviors, thoughts, and intentions that are undertaken to reduce suffering both for oneself and others (McDonald, 2000; Wilks, 2014). In the context of the treatments for Beth and Amy undertaken for this study, the term Skillful Means refers to behaviors that allow the client to respond to experience in a way that facilitates engaging with present experience in a pragmatic, non-evaluative, and compassionate manner.

The purpose of cultivating skillful responses (via Skillful Means) in the A/AMCS model is twofold. First, the application of skillful responses to a given situation will serve to pragmatically reduce the client's suffering; the client will engage in more situation-appropriate, adaptive behavior. Second, the therapist and client collaboratively determine skillful responses so that the client will, eventually, be able to intuitively determine his or her own skillful responses without the aid of the therapist. Generalization of the process by which the client determines skillful responses is also a necessary function of this intervention, as a skillful response in one context is not necessarily a skillful response in a different context.

The interventions described above all serve to cultivate the client's ability to: (a) bring awareness to present experience, (b) without trying to change or alter experience, (c) and respond in situation-specific, adaptive ways. All three components of treatment serve to reduce the client's tendencies of experiential avoidance and experiential attachment while increasing the client's ability to act in ways that respond skillfully to the present situation. 
Pragmatic Case Studies in Psychotherapy, http://pcsp.libraries.rutgers.edu

Volume 12, Module 4, Article 1, pp. 238-308, 12-16-16 [copyright by author]

\section{$\underline{\text { Research Support for the A/AMCS }}$}

While the A/AMCS has not yet been tested as such in clinical settings (given that it was developed for this study), several components of the A/AMCS have been clinically examined as part of other mindfulness-based interventions. For example, both Mindfulness-Based Stress Reduction (MBSR; Kabat-Zinn, 1990) and Mindfulness-Based Cognitive Therapy (MBCT; Segal, Williams, \& Teasdale, 2012), which share the A/AMCS's conception of suffering and how suffering occurs, have large bodies of evidence supporting that they are effective clinical interventions. MBSR was found to improve psychological functioning in populations with both somatic distress and mild psychological distress (de Vibe, Bjorndal, Tipton, Hammerstrom, \& Kowalski, 2012) and has been shown to reduce stress in healthy individuals (Chiesa \& Seretti, 2009). Additionally, MBCT has been found to be effective in preventing relapse from recurrent Major Depressive Disorder (Piet \& Hoogard, 2011) and has been found to reduce symptoms of anxiety in recurrent Bipolar Disorder (Chiesa \& Serretti, 2011).

Components of the A/AMCS, such as mindfulness practice, the cultivation of acceptance, and the conceptualization of how attempts to change present experience lead to suffering, are also integral components of current effective psychotherapies. Acceptance and Commitment Therapy (Hayes, Strosahl, \& Wilson, 2011), which utilizes acceptance as one of its primary intervention strategies, has been shown to be efficacious in treating both mood and anxiety disorders (Swain, Hancock, Hainsworth, \& Bowman, 2013) as well as improving psychological functioning in individuals with chronic pain (Wetherell et. al., 2011). Additionally, Dialectical Behavior Therapy (Linehan, 1993), which uses mindfulness practices as a primary skill taught as part of treatment, has been shown to reduce suicidal and parasuicidal behavior and increase treatment compliance in individuals with Borderline Personality Disorder (Panos, Jackson, Hasan, \& Panos, 2014). All in all, Dialectical Behavior Therapy is considered an empirically supported treatment for Borderline Personality Disorder by the APA Society of Clinical Psychology (Society of Clinical Psychology, 2014).

\section{Integration of TLDP and the A/AMC}

The type of integration that was planned to take place between TLDP and the A/AMCS is "assimilative integration" (Messer, 1992). Assimilative integration incorporates the attitudes, perspectives, or techniques of an auxiliary therapy into a therapist's primary approach (Messer, 1992). In the present model, A/AMCS was developed as a new adaptation of Buddhist ideas to be integrated into-and in the process to enhance- the established "home theory" of TimeLimited Dynamic Therapy (TLDT). Following Lampropoulos's (2001) suggestion that effective assimilative integration takes place when there is deliberate action integrating the two perspectives, I identified two areas in which the A/AMCS can be integrated into TLDP.

Integration with the TLDP's Case Formulation, the Cyclical Maladaptive Pattern (CMP)

The first way involves TLDP's approach to case formulation. As mentioned above, case formulation in TLDP centers on the construction of a Cyclical Maladaptive Pattern (CMP) for the client, and it involves five components: (a) Acts of the Self; (b) Expectations of Others' Reactions; (c) Acts of Others Toward the Self; (d) Acts of the Self Toward the Self; and (e) the 
Pragmatic Case Studies in Psychotherapy, http://pcsp.libraries.rutgers.edu

Volume 12, Module 4, Article 1, pp. 238-308, 12-16-16 [copyright by author]

Therapist's Interactive Countertransference. In addition to the five standard sections of the CMP, a sixth section was added that examines the client's attachment to feeling states and avoidance of aversive experience.

Two main questions are answered in this sixth section. First, what beneficial or desired emotional states is the client attempting to achieve? Second, what aversive feeling states is the client turning away from? Rather than examining the interpersonal interactions themselves, this area examines the affective response that the client was trying to obtain through engaging in a specific interpersonal behavior. For example, what are the feeling states produced by the client's interactional pattern that the client is attempting to re-experience? What current affective states is the client attempting to avoid by engaging in his or her maladaptive relational patterns? By examining the function of the client's relational patterns, information can be gathered regarding both the pleasant experiences that are being searched for and the aversive experiences that are being avoided.

This new, sixth section of the CMP adds two components that are not currently fully explored in the individual formulation. First, examining this section re-conceptualizes the reason for the client's initial behavior which created his or her maladaptive relational pattern. In the original CMP, the client's initial relational behavior is conceptualized as caused by introjects that the client developed early in life. The additional section enables the clinician to more deeply examine introjects by analyzing the affective states that are caused by introjected objects. Additionally, the clinician is better able to understand the once-adaptive function of the client's introjects by examining the feeling states that the client is attempting to obtain through their relational behavior.

The second way the additional CMP section more fully explores the client's maladaptive relational patterns is by amending the middle portion of a maladaptive relational cycle. The new section of the CMP brings more focus to the affective states that arise in the client because of his or her interpretation of events. Specifically, the focus is on the emotion that is being avoided when the client reacts to another person's actions. For example, if a client frequently reaches out for emotional contact after having plans cancelled, the clinician's focus would be the client's emotional reaction to having plans cancelled and the way in which the client was attempting to avoid aversive emotional experience.

\section{Integration with the TLDP's Intervention Goals}

Interventions that are incorporated from the A/AMCS are designed to aid in achieving TLDP's goals of new interpersonal/intrapersonal insight and experience. Mindfulness is incorporated in order to aid in both the development of new insight through paying attention to the unfolding of moment-to-moment experience and the new intrapersonal experience of sitting with experience rather than attempting to immediately change or alter experience. The client is formally instructed in eight half-hour mindfulness sessions immediately prior to weekly individual therapy sessions 6-13. As mentioned above, these sessions are modeled after the eight-week programs of Mindfulness-Based Stress Reduction (MBSR; Kabat-Zinn, 1990) and Mindfulness-Based Cognitive Therapy (MBCT; Segal, Williams, \& Teasdale, 2012), with the focus of practice moving from awareness of the breath and body, to awareness of thoughts and, 
Pragmatic Case Studies in Psychotherapy, http://pcsp.libraries.rutgers.edu

Volume 12, Module 4, Article 1, pp. 238-308, 12-16-16 [copyright by author]

finally, to informal practice. Following formal meditation exercises, the therapist engages in mindful inquiry with the client, which serves to aid the client in processing his or her experience during the meditation, while at the same time modeling mindful responses to thought and emotion (Woods, 2013). The concept of mindfulness, as well as the process of Turning Towards present experience, is also referenced as appropriate during therapy sessions. The exploration of Skillful Means in any given situation is incorporated into treatment in order develop pragmatic behavioral strategies which serve to circumvent the client's Cyclical Maladaptive Pattern and provide the client with alternative, more adaptive interpersonal behaviors.

\section{Therapist Characteristics}

As a clinician, I have had experience in treating patients using both TLDP and mindfulness-based interventions like Mindfulness-Based Stress Reduction (MBSR) and Mindfulness-Based Cognitive Therapy (MBCT). At the time of the treatments described below, I was entering my fourth year of graduate study in clinical psychology and already had three years of experience providing relational psychodynamic therapy to clients. Additionally, I had completed a five-day residential training in MBCT with its developer, Zindel Segal, and two full eight-week courses of MBSR. I also had a formal meditation retreat experience at the Insight Meditation Society (https://www.dharma.org), one of the foremost meditation and Vipassana retreat centers in the United States. At the time of treatment, I had cultivated a daily meditation practice for the previous three and a half years.

\section{4a-6a. BETH'S VERY POSITIVE OUTCOME THERAPY¹}

\section{4a. Assessment of Beth's Presenting Problems, Goals, History, and Strengths}

\section{$\underline{\text { Presenting Problems }}$}

Beth presented for treatment exhibiting several symptoms of major depression, including fatigue, difficulty maintaining sleep, reduced self-worth, passive suicidal ideation, and anhedonia. In addition to these persistent symptoms, Beth experienced periods of acute self-hate and feeling "emotionally out of control.” When feeling “emotionally out of control,” Beth occasionally engaged in self-harm behavior consisting of choking herself until she felt more "in control" of her emotions. Beth had engaged in self-harm behavior twice in the year before the beginning of treatment, with the most recent occurrence taking place two months before treatment. Beth was most liable to experience "out of control” emotions when she felt invalidated or rejected by her boyfriend, though she said that, "I know he probably didn’t act that way on purpose, I'm just super sensitive.” When her boyfriend engaged in behavior that Beth experienced as invalidating, she would think to herself, "It makes sense that he hates me because I'm not someone who deserves to be loved or respected." Beth would then escalate her selfcritical thoughts and "end up needing to do anything to stop me from feeling the way I was

\footnotetext{
${ }^{1}$ The next six sections are numbered 4a-6a to indicate their parallel to sections 4-6 of a typical pragmatic case study (Fishman, 2005)—specifically: 4) Assessment of the Client's Problems, Goals, Strengths, and History; 5) Formulation and Treatment Plan; and 6) Course of Therapy. Chapters 4a-6a describe Beth's therapy; and 4b-6b, to Amy's therapy.
} 
feeling.” At this point, Beth would either self-harm or "cry so much that I just got exhausted and fall asleep." Her boyfriend typically attempted to comfort her when she was in a period of acute sadness, but was only sometimes successful in making her feel better.

Beth also expressed negative views about her body, saying that she should "be thinner than I am right now." She had previously been treated for Bulimia Nervosa and, while she did not engaging in binging or restrictive eating, she said that "I still feel like my body's not good enough.” Beth said that she felt "way better about my body than I used to," and identified her previous therapy as being "really helpful” in addressing her disordered eating, despite still feeling that her body is unattractive. Beth's negative body image would become stronger during periods of intense stress and after a period of her feeling emotionally out of control.

\section{Quantitative Assessment}

At the beginning of treatment, Beth filled out five standardized quantitative measures, three of which measured symptoms and two which measured traits associated with treatment. The three symptom-based measures (the OQ-45, the BDI, and the BAI, see below) were given every week of treatment immediately prior to therapy sessions. A measure of therapeutic relationship (the WAI, see below), was given every other session, starting in session 3 . Two traitbased measures (the MAAS and the NAS, see below) were administered. Since these two measures were examining relatively stable areas of Beth's life experience, they were only administered twice, at the beginning and end of therapy.

Outcome Questionnaire-45 (OQ-45; Lambert et al., 1996). In order to better assess Beth's general level of functioning and symptom distress, she was given the OQ-45 to complete every session. The OQ-45 is a 45-item self-report measure that has three subscales: Symptom Distress, Interpersonal Relations, and Social Role. It also has a combined Total Score as a measure of overall functioning. (For Beth's scores, see Table 2.)

Two of the symptom-focused measures were based on of Beth's presenting problems. Given that Beth was presenting with both depressive symptoms and anxiety over interpersonal issues, she was given these types of measures, as described below.

Beck Depression Inventory-Second Version (BDI-II; Beck, Steer, \& Brown, 1996). This measure is comprised of 21 items which are scored from $0-3$, with a higher score indicating more severe levels of depression. A score of 0-13 indicates minimal depression, 14-19 mild depression, 20-28 moderate depression, and 29-63 severe depression. (For Beth's scores, see Table 3.)

Beck Anxiety Inventory (BAI; Beck \& Steer, 1993). This measure is also comprised of 21 items (scored from 0 to 3 points) with a higher score indicating more severe anxiety symptoms. A score of 0-7 indicates minimum levels of anxiety, 8-15 mild anxiety, 16-25 moderate anxiety, and 26-63 severe anxiety. (For Beth's scores, see Table 4.)

Working Alliance Inventory-Short Form (WAI-S; Tracey \& Kokotovic, 1989). Given that the treatment examined in these case studies was relational in nature, the WAI-S was given 
Pragmatic Case Studies in Psychotherapy, http://pcsp.libraries.rutgers.edu

Volume 12, Module 4, Article 1, pp. 238-308, 12-16-16 [copyright by author]

every other session in order to measure Beth's perceptions and attitudes regarding the therapist and therapeutic relationship. The WAI-S is a 12-item self-report measure that has three subscales—Task, Bond, and Goal—and a Total Score. (For Beth's scores, see Table 5.)

While the abovementioned measures assess Beth's functioning in relation to the impact of the more traditional short-term dynamic therapy component of treatment, I was also interested in assessing the impact of the mindfulness and Buddhism-based interventions on Beth's functioning. This was done through the administration of the two measures presented below.

Mindful Awareness Attention Scale (MAAS; Brown \& Ryan, 2003). This measure is a 15-item self-report measure that assesses dispositional mindfulness, or the open, receptive awareness of and attention to what is taking place in the present moment (Brown \& Ryan, 2003). Each item is rated 1-6 and then a mean is calculated, with higher numbers representing higher levels of dispositional mindfulness. (For Beth's scores, see Table 6.)

Nonattachment Scale (NAS; Sahdra, Shaver, \& Brown, 2010). This measure is a 30-item self-report scale that is designed to assess the Buddhist concept of non-attachment, defined as an absence of fixation on ideas and sensory objects, and an absence of internal pressure to change, avoid or grasp experiences. (Sahdra, Shaver, \& Brown, 2010). Similarly to the MAAS, each item in the NAS is rated 1-6 and a mean of total scores is calculated, with higher scores representing higher features of Buddhist non-attachment. (For Beth's scores, see Table 7.)

\section{$\underline{\text { Relevant Personal History }}$}

Beth grew up with her mother, maternal grandmother, and younger brother in the suburbs of a large city in Maryland. She was conceived out of a long term affair a man had with her mother (her brother has the same father) and has never lived with her father. Beth's father would visit the client and her mother bi-weekly, but never stay "more than a few days." She said that she has a "complicated" relationship with her father and, while she enjoyed his visits when she was young, she still has "a lot of anger towards him." Beth said that she was always aware that her father had "another family that he would come home to every night" and felt that it was "hard to know that you're part of the 'other' family."

Beth had a "sometimes tumultuous" relationship with her mother growing up, saying that she "always" felt loved and supported by her mother, but frequently argued with her mother "over the smallest things," especially when Beth was in middle and high school. When Beth first began experiencing depressive symptoms and suicidal ideation while in middle school, her mother "wasn't really sure what to do with me or how to help me." Beth said that her mother suggested that she try therapy, but was never able to find a therapist with whom Beth felt comfortable and was able to improve her functioning. Frequently, when Beth would become upset or exhibit disordered eating behavior while finishing high school and beginning college, her mother would begin crying and try to "convince me that I didn't have to do this stuff to myself." Beth would then become upset and "feel bad for doing that stuff to my mom."

Beth was active in her social circle while in middle school, but reported that many of her friends in middle school began bullying her in high school "and I still have no idea why." She 
had a small but close social circle in high school, though she became distant with those friends when her depression worsened upon entering college. Beth has had two romantic relationships, both occurring after she began college. She dated her first boyfriend during her freshman and sophomore years of college and ended the relationship after her boyfriend refused to reduce his marijuana and cocaine usage. Beth reported that her then-boyfriend never "really pushed" her to join him in his drug use and was not verbally or physically abusive while using, but she felt that she needed to end the relationship because "he was always lying to me about using drugs and always trying to get out of the lies he would put himself in.” At the time of treatment Beth had been dating her current boyfriend for approximately two years and recently moved in with him in central New Jersey, where he was completing a doctorate in engineering. She reported being "very happy" with the relationship, though there were times when she felt her boyfriend did not pay enough attention to her which caused her to feel "very lonely.” Beth said she didn't generally express this loneliness to her boyfriend and "keeping it inside" sometimes led to feelings of low self-worth and impaired self-image.

\section{Presentation at the Beginning of Therapy}

Beth began treatment with me shortly after moving in with her boyfriend from her mother's house and was experiencing a worsening in her depressive symptoms because she was feeling "kind of lonely moving to a new place." When she was living with her mother, immediately following her college graduation, she was in therapy to address Bulimia Nervosa with a clinician who encouraged her to continue treatment after her move, which led Beth to contact my clinic for further treatment. Beth appeared comfortable during our first few sessions and was able to clearly and succinctly tell me about her current problems. As I have mentioned previously, she had been in therapy three previous times before our treatment and said that her seeming comfort speaking about her problems came from "getting used to talking about this kind of stuff before."

While Beth clearly seemed comfortable speaking about both her presenting problems and history of problems, there were times when her affect did not seem to match the content of her speech. For example, Beth would maintain a calm composure and steady affect while speaking about feeling disappointed in her mother for "freaking out and sort of leaving me alone" when Beth was in acute distress while she was younger. When I first brought up this seeming disconnect between affect and content Beth wasn't sure what I meant and, after my making this observation a few more times over the first number of sessions, Beth admitted that she didn't "really see what the point is of me getting all upset about it to you in here, it's not going to make things better." In line with this treatment's focus on examining and addressing experiences that are aversive, this hesitancy to experience affect in the moment was addressed and explored later in therapy.

\section{Diagnosis}

At the beginning of treatment Beth presented with symptoms meeting criteria DSM-5 criteria for a Major Depressive Episode, including depressed mood most of the day nearly every day, anhedonia, fatigue, feelings of worthlessness, passive suicidal ideation, decreased appetite and concentration difficulties. In addition to causing her significant personal distress, her 
symptoms were contributing to conflicts with her boyfriend and causing Beth difficulty in searching for a job. Because Beth had experienced four Major Depressive Episodes since the age of twelve, she also met DSM-5 criteria for Major Depressive Disorder, Recurrent, Moderate. Beth had previous treatment for Bulimia Nervosa and, while she presented with markedly reduced appetite and negative body image, an eating disorder diagnosis was not given because Beth did not engage in compensatory or restrictive eating and these symptoms can reasonably be attributed to a Major Depressive Episode.

\section{$\underline{\text { Strengths }}$}

Beth presented with myriad strengths that indicated the possibility for a positive treatment outcome. She had been in therapy three times prior to our treatment and was able to clearly articulate what she found helpful and unhelpful, allowing us to have an open conversation about the expected nature of treatment. She also felt very comfortable being open about her experiences and problems. Though Beth had recently moved several hundred miles from home, she saw her boyfriend as a very supportive presence in her life and frequently utilized him for his support and comfort. Additionally, despite her symptoms, Beth was able to maintain her interpersonal skills and effectively and appropriately interacted with others. Finally, Beth was highly motivated for treatment and strongly desired change and improvement in her life.

\section{5a. Beth's Case Formulation and Treatment Goals}

\section{Case Formulation: The Cyclical Maladaptive Pattern (CMP)}

In line with the integration model outlined in Section 3, Beth's case formulation included all five sections of formal case formulation found in TLDP and included an extra section regarding her pattern of attachment to pleasant experience and aversion to unpleasant experience.

- Acts of the Self: Beth was scared of disappointing others and felt like "a crazy person" when others noticed her emotional state. When she felt unable to express her emotional state and needs, she felt acutely upset, out of control, and alone. In order to "keep things under wraps," Beth acted polite but distant with others and kept people "generally at an arm’s length."

- $\quad$ Expectations of Others’ Reactions: Beth expected others to be rejecting and disinterested in her. When I asked her if she has ever thought about telling others about her experience, she said that "no one's interested in hearing me talking about myself." Beth expected that others would be "unable to handle" her should she become emotional or upset; she unconsciously saw the other as fragile and incapable of soothing her.

- Acts of Others Toward the Self: Beth said that her boyfriend "wouldn't notice me" when she was upset, even though she felt that her distress was "pretty clear." She also reported that there were numerous times in both middle school and college when, upon seeing Beth exhibiting depressive symptoms or engaging in disordered eating, her mother would begin crying and say, "I just don’t know how to help you." 
Pragmatic Case Studies in Psychotherapy, http://pcsp.libraries.rutgers.edu

Volume 12, Module 4, Article 1, pp. 238-308, 12-16-16 [copyright by author]

- $\quad$ Acts of the Self Toward the Self: Beth felt that she was "too much to handle" when she got "emotional" and felt "demanding" and "crazy." She felt that she was "not someone people should be interested in" and should not be cared for by others.

- Interactive Countertransference: While working with Beth, I frequently felt the need to provide immediate relief to her suffering, though I was ultimately unsuccessful whenever I attempted to "talk her out" of any low mood she was experiencing. Consequently, I would feel that I was wholly unable to help her and become frustrated when experiencing this helplessness.

- Attachment/Aversion Patterns: When Beth experienced her strong unconscious fears of rejection and abandonment by others, she attempted to avoid these experiences through rumination and self-criticism. In order to maintain the feeling of relative safety, Beth was polite, but guarded in relationships. In rare cases, when she was in extreme distress, she would resort to non-lethal self-harm in order to regain the feeling of safety.

Treatment Goals and Planned Phases of Treatment

Consistent with treatment goals of TLDP, the primary aim of the treatment was to provide Beth with explicit new intrapersonal/interpersonal understanding and experiences in order to alter her CMP and enable her to engage in more adaptive interpersonal functioning (Levenson, 1995, 2010). In order to facilitate new intrapersonal understanding, I encouraged Beth to bring attention to her affective experience in the moment, with special attention paid to any attachment needs that were arising during the session. By bringing a focus to Beth's affective states in sessions, she was able to gain a new understanding of what her attachment needs are and what affective states arise in conjunction with those attachment needs. Related to this goal, treatment provided Beth with new intrapersonal experiences through a focus of resting attention on the present moment without actively trying to change experience. In line with this, Beth and I attempted to collectively move toward her experience rather than avoid any aversive experience. Through this process, Beth had the experience of being with her internal states and habituating to her experience without the knee-jerk reaction of trying to alter unpleasant experiences. This specific intrapersonal experience is similar to the affective exposures found in Leigh McCullough’s Treating Affect Phobia (McCullough, Kuhn, Andrews, et. al., 2003).

Treatment attempted to provide Beth with new interpersonal understanding by bringing to attention how her hesitancy to let others in on her internal experience is preventing her needs from being met. Additionally, by analyzing Beth's interpersonal interaction within and outside of therapy, Beth would come to see how her "out of control” and tearful behavior, though seemingly out of her control, is ineffective at indicating to others what her needs are in the moment and how to meet those needs. Finally, Beth would be provided with new interpersonal experiences through our interactions in therapy. I encouraged Beth to focus on her own experience of our interactions and track what her interpersonal needs might be in any given moment. After she was successfully able to identify her needs, we would have a conversation about expressing those needs to me in an effective way. I would then be responsive as clinically appropriate in the moment, providing Beth with a complete interpersonal interaction in which 
she noticed her interpersonal needs, communicated those needs to the other member of the interaction, and then got those needs met.

The above four overarching goals were embedded in a four-phase treatment model, with each phase having discrete goals leading to the four main treatment goals described above:

\section{Phase 1 Treatment Goals}

- GOAL I: Orient Beth to TLDP; identify the five sections of Beth's CMP and discuss with Beth how her CMP is contributing to her psychological distress.

- GOAL II: Explain the Aversion/Attachment (a/model to Beth; elucidate the ways in which Beth is avoiding aversive experience and striving for positive experiences; introduce the concept of mindfulness meditation as a way of countering attachment/aversion tendencies.

\section{Phase 2 Treatment Goals}

- GOAL III: Introduce Beth to mindfulness practice via eight 30-minute mindfulness training sessions immediately prior to therapy sessions; incorporate the practices of staying with experience and responding to emotion in therapy sessions.

- GOAL IV: Examine Beth's proclivity towards self-criticism and self-hate in relation to any fears or desires she may be experiencing immediately prior to self-critical behaviors; work towards bringing awareness and acceptance to any of these affective experiences prior to Beth engaging in self-hate

- GOAL V: Introduce Beth to the idea of responding, rather than reacting, to experience; identify ways that Beth could respond to specific interpersonal situations that are raised in therapy.

\section{Phase 3. Treatment Goals}

- GOAL VI: Encourage Beth to express her interpersonal desires and needs within the therapy; examine any resistance or hesitance towards expressing her wants and desires in therapy.

- GOAL VII: Observe and discuss instances of Beth noticing her needs in relationships and having difficulty effectively expressing those needs; continue "sitting with" any discomfort that may arise in the course of recognizing and expressing those needs.

\section{Phase 4. Treatment Goals}

- GOAL VIII: Introduce the concept of skillful means; collaboratively examine Skill Means - that is, skillful and adaptive responses - to interpersonal situations wherein Beth feels that her needs are not getting met. 
Aversion/Attachment Model of Client Suffering: The Cases of "Beth" and "Amy" J. M. Samlin

Pragmatic Case Studies in Psychotherapy, http://pcsp.libraries.rutgers.edu

Volume 12, Module 4, Article 1, pp. 238-308, 12-16-16 [copyright by author]

- GOAL IX: Generalize Beth’s skillful responses to a variety of different interpersonal and intrapersonal situations; encourage Beth to generate and implement skillful means without the therapist's guidance and prompting.

- GOAL X: Consolidate Beth's treatment gains and discuss how Beth can continue to practice and implement what she has learned in therapy once the treatment has ended.

\section{6a. Beth's Course of Treatment}

\section{Phase 1: Sessions 1-5}

Prior to the first session of formal treatment, Beth and I met twice for two one-hour intake sessions. During this time, I collected background information, took a history of her presenting problems, and oriented her to the general outline of how treatment would proceed, suggesting a treatment length of 20-24 sessions. Because of this pre-orientation to treatment, the focus of the first few sessions was not exclusively information gathering, but also about beginning the process of bringing Beth's attention to what was going on in the room.

Beth began session 1 by talking about feeling lonely when she was at home during the day. She said that she doesn't "really like myself for company” and that when her boyfriend would come home and wasn't doing school work, "There was this little part of me that was pleading for him to come talk to me or sit down with me." This seemed like a genuine and deep attachment fear that she would be abandoned and left alone by her boyfriend and be unsure of what to do by herself. I asked Beth what she was noticing as she was talking about that fear in session and, as would become a theme in treatment, Beth engaged with the question in a more cognitive, rather than affective, way, saying “I'm not sure why I'm like that. I don't know why I react that way.” If this response occurred further along in treatment I might have brought Beth's attention to the intellectual nature of her response, but this early on in treatment I was focused more on empathically mirroring her experience, whether it was cognitive or affective.

Beth demonstrated her tendency to self-criticize at the beginning of session two. At the beginning of the session there was a short, 6-second silence, during which Beth appeared uncomfortable and was looking around the room. I asked her what her experience of the silence was and she said that she was "unsure what to say next." Despite us both participating in the silence, she said that she "didn't know what to do" while the silence was going on and felt like she should have started talking. I pointed out that it seemed like she was taking on a lot of responsibility for the interaction and she said that she always feels "like it's my fault if some interaction doesn't go right." Beth went on to talk about her fear that social interactions will end up “damaging” her in some way.

During this conversation, while Beth was talking about her anxiety surrounding the potential damage a social situation can cause, I periodically checked in with her to find out about her present experience. When I would ask these questions, Beth would answer intellectually ("I don't know what's wrong with me") rather than talking about the anxiety that seemed to be present. About halfway through the session, I oriented Beth to the Aversion/Attachment Model of Client Suffering (hereafter sometimes referred to simply as the "aversion/attachment model," 
Pragmatic Case Studies in Psychotherapy, http://pcsp.libraries.rutgers.edu

Volume 12, Module 4, Article 1, pp. 238-308, 12-16-16 [copyright by author]

explaining how people tend to move away from experiences that are unpleasant and the possible consequences of not staying with present experiences. I felt that it was appropriate at that time to explain the aversion/avoidance component of treatment because we were in the process of talking about the ways in which interpersonal experience can be so painful for Beth. By providing context to Beth's tendency to move away from aversive experience, I was not only orienting her to an important component of treatment, but also normalizing her experience and framing it as something that can be explored, rather than rejected.

In the following session (session 3), Beth talked about a "meltdown" she had over the weekend which led to her hitting and choking herself for the first time in six months As Beth was explaining what happened over the weekend, I focused on reflecting the fear and sadness that she brought up in the room. At various points in telling the events Beth's voice broke and she began crying softly. I wanted to bring attention to her affect because Beth was engaging in a new way of relating to me; that is, infusing emotion into her retelling of events rather than simply reciting events. I felt that it was important to slow down the session and bring awareness to the affect in the room, both as a way to implicitly grant permission to express that affect and begin to develop some comfort in holding that affect.

As the session progressed Beth talked about how she is quick to "take the blame" if something goes wrong in an interaction and expressed amazement that anyone would care about her, saying, "I don't understand why people love me, but I guess I can intellectually acknowledge that they exist.” It is possible that, in reaction to anxiety at expressing such emotion with me in session, Beth was moving to a more comfortable, yet distressing, place of self-hate. In line with the TLDP treatment principle of recognizing and utilizing countertransference reactions (Levenson, 2010), I shared that I was grateful Beth was so expressive in therapy and felt more connected to her when she brought more of herself into the room. I hoped that this intervention would provide Beth with a different reaction to affective expression than what she was accustomed to; rather than moving away from her when she expressed vulnerability, like her mother and boyfriend, I was communicating that I felt closer to her after she expressed vulnerability. After I disclosed this reaction, Beth said that she felt "confused” and "surprised” that I didn't think she was a "train wreck."

While Beth did not experience any other “meltdowns” between sessions three and four, she continued to talk in session 4 about times in which her frustration with others led to her quickly turning that frustration inward and becoming very self-critical. It was becoming clear to me that what she was really discussing was how she causes herself real and profound suffering through her reaction to experience.

I brought up the topic of the above-mentioned concept of the "second dart (Feldman \& Kuyken, 2011) and talked about how her tendency to experience "failing" as unacceptable was causing her profound suffering. I suggested that we begin to "slow things down" and "turn towards the things that seem to be a knee-jerk for you to move away from.” Beth responded by saying that her mind is "always going" and mentioned she heard that meditation was "a way that people slow things down.” Not wanting to pass up a golden chance, I took the opportunity to orient her to the practice of mindfulness meditation, explaining that it is "a way that we can 
practice slowing things down and opening ourselves up to what's really going on, while at the same time noticing what our minds are up to and how we tend to react to experiences in similar ways.” I also informed Beth of the mindfulness pre-session practice we'd be engaging in and we agreed to start these practices at the sixth session. By the end of session 4, I felt that Beth was sufficiently oriented to the pertinent components of the aversion/attachment model, but I still wanted to explore more of Beth's Cylical Maladaptive Pattern (CMP) before moving on to phase two of treatment.

In session 5, when talking about her new job as a waitress, Beth said she was "shocked" that her coworkers helped her during a time when she felt particularly overwhelmed. I asked if she is used to the experience of getting rejected, and she talked about times when she was younger during which her mother would begin crying and say "I don't know how to help you" when Beth expressed extreme distress and exhibited disordered eating. Beth said that there have been "lots of times I've refrained from expressing what I've felt ... [because I was worried that I was] too much to handle" and was scared of "placing that kind of emotional burden on people." The following exchange summarizes nicely the interpersonal fear that Beth held regarding expressing emotion in therapy:

Jason: What would happen if you tried to express negative emotion to me or to other people?

Beth: I would be showing people a side of me I don't want them to see.

Jason: Don't want me to see? [Beth nods.] So in a way you're protecting me just like you're protecting everyone else.

Beth: Having those feelings makes me feel like a crazy person.

Jason: What are you worried my reaction's going to be?

Beth: That I'm a handful, that I have a lot of feelings. I'm always afraid that the other person won't be able to take me.

This exchange demonstrates how Beth's previous experiences led her to fear that others would react with the same distress as her mother and not be able to "take" her. Due to these previous experiences, she internalized her emotions, and experiencing those emotions, as proof that she is "crazy" and fears that others will share that view were she to express her emotions. By the end of session 5, I felt that Beth was oriented to both the A/AMCS and TLDP models and that her CMP was elucidated enough to begin the next phase of treatment.

\section{Phase 2: Sessions 6-13}

Immediately prior to session 6, Beth and I met for our first mindfulness practice session. Each practice session lasted for thirty minutes, after which we had our regular therapy session. For a summary of the mindfulness practice sessions, see Table 8.

In session 6, Beth talked about a realization that "hit" her during the past weekend after feeling like she did not stand up for herself enough during an interaction with a cashier, which 
Pragmatic Case Studies in Psychotherapy, http://pcsp.libraries.rutgers.edu

Volume 12, Module 4, Article 1, pp. 238-308, 12-16-16 [copyright by author]

annoyed her boyfriend. She was "beginning to get down” when she had thought, "Wait, all I did was respond with emotions in the situation and for some reason [my boyfriend] was being weird about it. That's his problem, not mine." After sharing this realization, she went on to say that "there's nothing wrong with feeling emotions, I'm allowed to have feelings." She concluded the story by sharing that she was beginning to see how "beating myself up over having these feelings makes them worse."

That these thoughts occurred to Beth immediately following a mindfulness practice session served to indicate to me that there seemed to be a "cross-fertilization" occurring whereby Beth was incorporating mindfulness practice experience into therapy (as was the hope at the outset of treatment). Additionally, we came back to these realizations throughout the course of treatment as a way to prove to Beth that she could, in fact, have these experiences and allow herself to be okay with whatever she was experiencing.

The focus of sessions 7 and 8 shifted slightly to Beth's expectations and fears of "putting herself out there" and affectively engaging in relationships. In session 7, Beth spoke about how she visited her mother over the weekend (who was living several states away), which brought up "a lot of old stuff for me around body image and feeling crazy." We discussed her mother's reaction when Beth would express negative affect about her body and Beth said that "nothing good" would come from expressing negative emotion to her mother; she said that her mother would get overwhelmed and "try to convince me that I was just being silly and unreasonable." In the course of our discussion, Beth said that, "even though I know that my body image stuff isn’t really logical, I never wanted to make her sad.” It struck me that this statement very powerfully indicated for Beth what the big risk was in showing negative affect to others; if she were sad, or even a little out of control, she would cause those she cared about in her life to suffer.

We more fully explored this idea in session 8 and spoke about Beth not "putting herself out there" emotionally in relationships. Beth talked about how she has "made a big effort" to distance herself from times of emotional discomfort "because they hurt so much." It struck me that, in order to begin to interrupt Beth's cycle of fearing that her affect would harm others, causing her to hold her emotions until they burst, we would need to begin to move closer towards those emotions in a systematic way.

I attempted to do this by turning the conversation towards the fear that she was "not normal" and that she would harm others when she would express negative affect. An exchange that occurred at the end of session 8 serves as a good example of the type of experience I was trying to cultivate in session. For much of the session, Beth was discussing her history of negative body image and how she has gone through periods of "really hating myself." I made a point of empathically reflecting the affect that was present, while keeping my voice level and sitting forward in my seat and minimizing the amount of "empathic clucking noises" (aww, mmm, etc.) that I made. At the end of the session, Beth said that she had "only really told my mom and my boyfriend the stuff I just told you." While staying forward in my seat and maintaining eye contact, I said, "Wow, thank you so much for letting me in on this stuff. You 
Pragmatic Case Studies in Psychotherapy, http://pcsp.libraries.rutgers.edu

Volume 12, Module 4, Article 1, pp. 238-308, 12-16-16 [copyright by author]

said before how difficult it is for you to talk about all of this and I really appreciate you sharing it with me.”

The purpose of this broad intervention was twofold. First, focusing on the affect that Beth was communicating served to further move us toward the aversive experience that she had previously been avoiding in session. Second, I hoped that my verbal and non-verbal behaviors communicated that I was present and receptive to her suffering while still able to withstand and handle the self-described "crazy" behavior that Beth felt she was communicating. This stanceempathetic, receptive, caring, but steady_was one that I would frequently take in treatment.

Beth continued the theme of sessions 7 and 8 into session 9, talking about how she is "terrified" of being complacent with her present condition and constantly wants to change and improve herself. Much of this pull for improvement centered on her body, and Beth said that “There hasn't been a day that goes by in two years where I haven't thought about doing something to change my body." While discussing her desire to change herself, Beth became tearful and spoke at a much quieter volume than previously in session. I reflected that it seemed like there was a strong emotional piece to her wanting to change her body, and she responded by saying that, “There's always been something emotionally wrong that's always been there and starving myself didn't fix it." Beth described how her mother would frequently try to convince Beth that she is "beautiful just the way you are," which would cause Beth to become very upset and feel "that out-of-control feeling."

I noticed that I was thinking of how Beth's mother was not meeting her needs when Beth expressed negative emotions and wondered if this was getting reenacted in treatment. Feeling fairly confident at this point of Beth's ability to move closer to her experience, I asked, "What did you want your mom to say? How would you have wanted to respond?" Beth responded that she would have preferred her mother to pretend that nothing was going on and "forget that it was happening." I wondered aloud if Beth was really expressing that she didn't want to be treated like "you were some crazy person," and she nodded and began softly crying. We processed this realization and, further keeping in line with my goal of fostering alternative interpersonal experiences in therapy, I proposed that we make a deal:

Jason: I'm wondering if we can make an agreement in here. You agree that we can really begin to move closer to what's going on, to really explore the experience of things for you; I'll agree to not treat you like you're nuts.

Beth: [laughing] Okay, that seems fair to me.

While this intervention might seem a bit blunt, I think that it served two important purposes. First, it communicated that I understood, on an implicit, non-verbal level, Beth's fear of being judged “crazy.” Second, I reframed the work of our treatment, Beth's opening to experience and the new interpersonal interactions I was attempting to foster, as a collaborative process for which we were both responsible. In a way, this was beginning to shift Beth from the role of the passive patient (who can't be helped) into that of the active participant in her own treatment. 
In session 10, Beth presented a test to my agreement to not "treat you like you're nuts." She said that she had two episodes of "spiraling out of control" in the past week, one of which led her to her superficially cutting the tops of her forearms. She said that she had never engaged in cutting before and was "so scared that I was just there on the floor, bleeding and crying into my boyfriend's arms.” Beth brought up a comment I made a few sessions earlier about her feeling invalidated by some of her boyfriend's comments and said that she was realizing that she did in fact sometimes feel invalidated by his comments.

During the process of Beth discussing these two episodes, we carefully examined and linked each discrete internal and external experience, similar to the "chain analysis" technique used in DBT (Linehan, 1993), that is, tracing the functionally related chronological sequence of a particular event or experience. The goal of this strategy was to explicitly identify Beth's functionally sequential reactions to external situations and internal events and to shift her experience from out of control and unknowable to observable and explicit. This intervention also served as a type of dyadic mindfulness meditation; we observed Beth's experiences, noticed her conditioned reactions to those experiences, and saw how her reactions and experiences formed a progression that led to her dysregulation.

Later in the session, I brought up Beth's tearfulness in the previous session and asked if the conversation felt helpful, attempting to gauge Beth's feelings around her previous emotional expression. She responded that while "it was nice to let things out," she didn't "see how expressing emotion can possibly help me.” Rather than further discuss the benefits of moving toward emotion, I chose to focus on what I saw as a re-enactment in therapy of her relationship with her mother, reflecting that there was a "sense of me wanting to help, and you wanting to work on stuff, but there's also a fear and expectation for you that 'I don't think this will be all that helpful."' This led to a discussion about Beth feeling more validated and helped when others respond with measured, empathic concern, rather than getting "all scared and reactive when I show times when I'm upset.”

Through this discussion, and a similar discussion in session 11 around Beth being unsure if her negative affect was expressing a need or "just me being unrealistically upset," we began to shift our conversations from her experience of others to the ways in which she might elicit others' reactions, and then have her emotional state be further influenced by those reactions. At the end of these discussions, Beth began understanding "that if I'm feeling something, and I let myself feel something, it frees me up to do something about it instead of just passively waiting to get rescued."

In sessions 12 ands 13, Beth's discussions were centered on her and her boyfriend getting a dog. In session 12, Beth discussed her frustration with her boyfriend around him "not really doing much during the whole adoption process" and said that she felt like she was "the only one who seemed invested in this.” This interactional style seemed to mirror that of her mother and father; her mother was the primary caretaker while her father would only occasionally enter her life, visiting from his "other” family. When they adopted the dog, between sessions 12 and 13, the dog reacted with "terrible separation anxiety," which led to Beth experiencing a great deal of anxiety and worry that “my dog is suffering and I don't know what's wrong and I don't know 
Pragmatic Case Studies in Psychotherapy, http://pcsp.libraries.rutgers.edu

Volume 12, Module 4, Article 1, pp. 238-308, 12-16-16 [copyright by author]

how to make it better." This experience seemed to mirror very strongly her mother's reaction when Beth would get upset; her mother would be unsure of what was wrong, not know what to do, and feel inept in her parental role.

Two events occurred, though, that served to stymie the re-enactment and produce an alternative, more positive outcome for Beth and her boyfriend. First, while Beth felt unsupported in the lead-up to her getting a dog, she reported that her boyfriend was extremely supportive and helpful; she said that it was "really nice to feel like someone's got my back." Additionally, she said that when she was feeling nervous about her dog, "he was right there with me because he was feeling nervous, too." When her boyfriend offered support by being "in it" with Beth, he was responding with the empathy and caring that Beth was looking for through her distress. Rather than exploring the re-enactment-and alternative conclusion - that was occurring between Beth and her boyfriend, I focused on her experience of getting her needs met in her relationship. Through examining Beth's positive attachment-need experience, Beth and I highlighted how she could, in fact, get her needs met, which meant "that I'm not necessarily the crazy person who can't handle emotions that I think I am.”

Phase 2 of treatment ended with Beth starting to internalize the lessons and experiences of the mindfulness practice sessions (though not formally practicing on her own). She was beginning to take ownership of her experience, rather than push it away, and seemed to be more readily acknowledging times when she had attachment needs and desires.

\section{Phase 3: Sessions 14-18}

In sessions 14 and 15 Beth demonstrated that she was still working with the concepts and practices taught in the mindfulness practice sessions (see Table 8). In session 14, Beth discussed her observation that, while there are times she gets upset, “there aren't as many extreme feelings as there were before. When things happen I don’t like, I just think to myself, 'well, this is happening, okay." She also said that she noticed herself becoming more "open” and "up front” when she was annoyed or frustrated with her boyfriend. This represented a fairly big shift in Beth's presentation; rather than turn her frustration inward, she was beginning to express and communicate her annoyance.

Her change in internal orientation seemed to engender different responses in others. In session 15, Beth discussed how, after she expressed guilt and distress over working in unpaid internship positions and not contributing "anything financially” to her relationship with boyfriend, both her mother and boyfriend provided support and reassurance that made Beth "genuinely feel better about things." Beth said that, though she cried at times while talking to her boyfriend and mother, "things never really felt out of control, I felt like I could handle myself.” I took this as an indication that Beth was beginning to open herself up to the dyadic regulation that had the opportunity to take place in her relationships. Much of the discussion that we had this session was focused around this support and how, when Beth opened herself up to her experience and was able to communicate her experience to others, she was able to get support that felt genuine and helpful. 
Following the previous two sessions of discussing Beth's seeming improvement in symptoms and change in interactional pattern, she presented to both sessions 16 and 17 in a dramatically different way.. In session 16, she had almost completely flat affect and said that for the past week, she had felt "numb, like I'm not really experiencing what is happening around me.” In talking about her experience, Beth said, “I can’t even remember feeling. It's weird, it almost feels like I lost a sense that I had, like if I lost an arm I would remember how to grab things, but I still couldn’t grab things because it's not there.” In addition to her near-alexithymic presentation, Beth responded to my questions and prompts with one- or two-word answers, which was very unusual for her, especially at this point in treatment.

This presentation was followed, in session 17, by Beth reporting that she felt "furiously bored with my life” and noted that her boredom was particularly strong towards her relationship with her boyfriend. Her boredom also extended to our treatment, with Beth saying that she didn't "really have anything to talk about" and that she did not have "any expectation that I'll get better." Interestingly, in both sessions 16 and 17 Beth denied any feelings of self-criticism, low mood, or self-hate.

Needless to say I was very taken aback by this dramatic shift in Beth’s presentation. After some brief questioning in session 16 about what might have caused such a shift (Beth said that these moments "sometimes just happen, and then I'll get over them"), I felt completely thrown and lost as to what to do next. I feebly attempted to explore whether Beth could "be okay with just what's happening, this lack of feeling”, but Beth responded with nonchalance and silence, two types of feedback that she had not given in the therapy at this point.

As session 17 progressed I was noticing myself feeling as if it was either up to me to make Beth's situation better or she was on her own; there was no sense of collaboration. Rather than bringing that dynamic up in the context of our relationship, I applied that feeling to Beth's relationship with her boyfriend. As Beth was discussing her boredom in her relationship, I asked:

Jason: What about telling your boyfriend that you're bored.

Beth: I don't want to do that. I'm not sure what I would expect him to be able to do about it. Jason: What about figuring out what to do together?

Beth: That's a novel idea. I always put it on either him or me to fix things, it's never together.

I then related this interaction pattern to the pattern that I was noticing (and feeling) in the treatment and wondered if there were times when "it's felt collaborative in here with me." Beth shared that the conversation we were having felt collaborative because, "we're not just trying to fix something, we're actually having a conversation.” We continued processing the interaction we were having and at the end of the session Beth commented that she was going to talk to her boyfriend about her experience because, “I didn’t want to hurt his feelings by bringing it up, but maybe he's feeling it, too.” 
In session 18, Beth indicated that our discussion the previous session bore fruit; she spoke to her boyfriend about her frustration with their relationship. Beth said that her boyfriend spoke a great deal about how he had felt in the relationship and, "pretty much said all the things" that Beth wanted him to say. As a result of this conversation, Beth said she felt like she "wasn't alone” in the relationship.

\section{Phase 4: Sessions 19-23}

In phase 4 of treatment, the therapy began to wind down to a close and I focused on processing issues of termination and generalizing the gains that Beth had made over the course of treatment. The work that went on during this phase seemed to be split relatively evenly into two categories: generalizing "Skillful Means" and processing termination.

Generalizing Skillful Means. As the therapy was ending, Beth was repeatedly demonstrating her ability to notice and allow herself to have her experience. In session 20, she discussed how she was more willing to "embrace all the things that happen to me" and noticed that she is "allowing myself to experience emotions rather than try and ignore them or power through them." She was being more forward with her disappointment (and happiness) with her boyfriend and said that she is able to "get annoyed and frustrated, and just move on." Further, Beth said that she has noticed her boyfriend is not trying to "help or fix" anything if she has a problem, which has helped her feel like "I don't need to fix all my problems immediately." At this point, I decided to formally introduce the concept of Skillful Means because Beth was showing that she was engaging with experience in ways that were reducing her suffering, opening her up to the possibility of responding, rather than reacting to experience (Rothberg, 2014). During our discussion of the ways in which she and her boyfriend were behaving differently, I said:

Jason: You know, a lot of what you're talking about right now is real similar to this concept called "Skillful Means." It's related to a lot of the mindfulness stuff that we've been going over and, essentially, what Skillful Means refers to is our ability to choose how to respond to situations when they come up. So all of this mindfulness practice that we've been doing [see Table 8] is all well and good, but we're not monks and we have to interact with the world and the way we can bring our mindfulness work to bear in our lives is by taking our ability to have a moment of pause when we're turning towards experience and think, "What's the most skillful way for me to respond here? What's the thing that I can do in this situation that will get my needs met and reduce some suffering?"

For example, when you were talking to your boyfriend about how pissed off you were the other day, that was a pretty skillful thing to do; you could've kept it in and had it fester, which used to happen a lot, but you knew you were frustrated and kind of said to yourself, "Why don't I just say it, it doesn't do me any good to keep it in." That's a great example of recognizing your experience and making a decision, even if it was preconscious, that ultimately led you to feel better." 
Pragmatic Case Studies in Psychotherapy, http://pcsp.libraries.rutgers.edu

Volume 12, Module 4, Article 1, pp. 238-308, 12-16-16 [copyright by author]

Beth responded that she “didn't realize I was already doing this stuff” and, during the remaining sessions, I pointed out moments when Beth was engaging in skillful action both with herself and with others.

We had our most in-depth discussion of her already-present skillful action in session 22. She was talking about her difficulties finding a new job and her worry that her mother would be "judgmental and make me feel terrible." Beth said that, two days prior to the session her mother called and asked her about her job search and Beth "had absolutely no interest in talking to her." During the conversation, though, Beth said she realized, "I was feeling really nervous about the whole thing, and I actually sort of did want to talk to her about it, so I just explained what was going on." She said that her mother reacted "really supportively and said that she was there for me in whatever way I needed." As we were examining this interaction, Beth recognized that "what I did was pretty skillful" and led to her mother "sort of reacting the way I hoped that she would've reacted." At the end of our discussion, Beth said that, "it seems like it's actually a lot easier to be skillful than unskillful, I just sort of feel what I'm feeling and do what I wanted to do in the first place."

Processing termination and the ending of the therapy relationship. The formal processing of termination began in session 19 when I mentioned to Beth that we had five sessions left. She said that she hadn't realized that "we had so little time" and commented that "goodbyes don't usually hit me until the end." Beth went on to say that when she is about to say goodbye in a relationship, "I'm almost in denial; it feels weird and disorienting a bit." This led her to be "pretty avoidant” when relationships are about to end.

As we were having this discussion, I thought that focusing on the termination of therapy during the last five sessions would serve two functions. First, by focusing on Beth's affect during termination, we would continue our process of "Turning Towards" an experience to which Beth had previously been extremely avoidant. Second, processing an ending and actually saying goodbye to a therapist (Beth had previously simply left treatment without much talk over the relationship ending) would give Beth the experience of saying goodbye in a relationship in a way that felt safe and comfortable.

One of the ways I attempted to do both of the above-mentioned processes was to ask if Beth wanted my opinion in matters related to our ending. In addition to allowing Beth the space to explore the experience of ending therapy, I was trying to subtly increase Beth's agency in the termination process. Beth had a history of being in a less-powerful position during the termination of interpersonal relationships (as exemplified by her father's frequent exiting of her life during her childhood and adolescence), and I hoped that asking if she was interested in my input during our termination would give Beth an experience of mastery during the ending of a relationship.

For example, in session 21 Beth was talking about her fear of "relapsing” after therapy and was wondering whether she should continue with another therapist after treatment was over. I asked if she wanted my opinion and this led into a discussion of her not being sure that she needed my opinion because "I kind of want to make this decision on my own; I think I trust myself to make the right decision.” I shared that I was pleased that she felt comfortable enough 
Pragmatic Case Studies in Psychotherapy, http://pcsp.libraries.rutgers.edu

Volume 12, Module 4, Article 1, pp. 238-308, 12-16-16 [copyright by author]

with herself to make this decision and that I experienced our discussion as very different from when treatment began. I also noticed that I felt much less pressure to fix things because she seemed so comfortable within herself, which seemed to mirror how her boyfriend reacted to her change in her interpersonal orientation to him.

During our final session (\#23), Beth and I continued this pattern of my asking how much she wished for me to insert myself into our ending. Beth was relaying her experience of the termination with her previous therapist and she said that, "My old therapist never actually told me what she thought of me or how she felt about us ending." I took this as an invitation and asked if she was interested in hearing my experience of our ending. Beth said that, "A few weeks ago when I was first thinking about this I wasn’t so sure, but I think I do.” I relayed how much I had enjoyed our working together and how I had looked forward to our meeting together every week. After I had finished speaking, Beth smiled and said, "I kind of hoped I had an impact on you. It's just nice to hear that.” That Beth was able to hear my positive feedback and respond by moving towards her experience of warmth and enjoyment was just as much an indication as any that I had seen of Beth's significant shift in her orientation to both herself and others. At the end of the session, as we were saying our goodbyes, Beth asked what her name would be in the case study. I asked her if she had one in mind and, as the reader has probably guessed at this point, she chose "Beth."

\section{4b-6b. AMY'S MODERATELY POSITIVE OUTCOME THERAPY}

\section{4b. Assessment of Beth's Presenting Problems, Goals, History, and Strengths}

\section{$\underline{\text { Presenting Problems }}$}

Amy presented for treatment in order to address what she perceived as communication difficulties between her and "the important men" in her life. She said that when she attempted to communicate with her father or boyfriend she experienced anxiety and had difficulty "getting out" what she was trying to say. This led Amy to feel "really intimidated" when she wanted to speak to her father or boyfriend about something and avoid situations in which she might need to speak to her father or boyfriend individually. For instance, Amy described experiencing anxiety when her father was washing his hands in the bathroom with the door open, feeling "too nervous to even go in and ask him if I could get my toothbrush." Amy said that talking to her father "felt like talking to someone that you don't know.” She also reported experiencing anticipatory anxiety prior to situations in which she might be left alone in "awkwardly silent" situations with her father. While Amy sometimes had difficulty communicating with her boyfriend, she attributed these difficulties to his "not really understanding where I’m coming from."

In addition to her anxiety related to communicating with her father and boyfriend, Amy experienced difficulty communicating her thoughts in professional situations when she experienced the other person as aloof and uninterested in her message. Amy felt "nervous a lot" while at work because she did not feel comfortable speaking to her boss, whom she believed “didn't really care about me or what I had to say." This led Amy to "be quiet in situations where I probably should've spoken up,” such as times when her boss asked if she was feeling 
Pragmatic Case Studies in Psychotherapy, http://pcsp.libraries.rutgers.edu

Volume 12, Module 4, Article 1, pp. 238-308, 12-16-16 [copyright by author]

overworked. Although Amy reported experiencing distress related to her communication difficulties at work, she emphasized that her relationship with her father and boyfriend constituted her primary reason for seeking treatment.

\section{Quantitative Assessment}

At the beginning of treatment, Amy filled out the same six standardized, quantitative instruments Beth was given: the BDI-II, the BAI, the OQ-45, the WAI, the MAAS, and the NAS. Since Amy's BDI-II score was initially quite low, this form was discontinued. All the other forms were administered in a manner parallel to those given Beth. For Amy's scores, see Tables 9-13.

\section{$\underline{\text { Relevant Personal History }}$}

Amy was born and raised in suburban New Jersey and grew up with her mother, father, and two older brothers (6 and 8 years older). She reported that she has always had a "close" relationship with her mother and felt like she could "tell her anything." Amy said that she had a "more distant" relationship with her father and has had difficulty talking to him for much of her life. She said that “it's never felt like he's abandoned me or anything, but I just don't feel like I can talk to him about anything." As an example, Amy said that when her mother would go away on a business trip she would feel "lonely" and "wish my mom would come back so I wouldn’t be stuck with my dad.”

Amy had a "cordial” relationship with her oldest brother, but did not interact with him much because of their age gap. She said that her middle brother would frequently make fun of her when she was young and teased her frequently about her weight. Amy experienced instances during her childhood and adolescence when she would feel "really separate" from her father and brothers, which most frequently occurred when they were “doing something I wasn't interested in, like watching sports." During instances when Amy felt "separate” from her father and brothers, she would be "unsure of what to do" and usually engaged in whatever activity her father and boyfriend were doing, “even though I knew I didn’t want to.”

Amy reported being "quiet” during middle school and high school and said she had a "tight-knit” group of friends to whom she still feels close. She graduated from a prominent southern university and said that she did not have "too many" close friends during college, but felt comfortable and supported. She began dating her first boyfriend in college, whom she described as "insecure in the relationship" and said that "communication between us was bad." Amy was in a relationship with her current boyfriend for 1.5 years at the time of treatment and said she had been dating him "seriously" for a year. Amy said that she and her current boyfriend had a "history" of breaking up and getting back together and were together for approximately four years after their most recent break-up. Amy said she was "happy" in her relationship, but that there were "some problems" which were "mostly down to communication"; she said that her boyfriend frequently did not communicate with her for an entire day, which upset her. She said that she and her boyfriend were "addressing the problems," though she admitted that her boyfriend's communication style was "really frustrating." 
Pragmatic Case Studies in Psychotherapy, http://pcsp.libraries.rutgers.edu

Volume 12, Module 4, Article 1, pp. 238-308, 12-16-16 [copyright by author]

\section{Presentation at the Beginning of Therapy}

Amy sought therapy after experiencing an incident at a wedding during which she became drunk and "cried at" her boyfriend, "without knowing anything about why I was so upset." She said that she was "really upset and confused" about this incident and, while discussing it with a friend, was told that she should "try" therapy. Amy attributed her tearfulness to her inability to speak candidly and openly to her boyfriend while she is sober. During the two pre-therapy intake sessions, Amy said that she was beginning to see that her communication difficulties with the "important men" in her life were taking a toll on her relationship and she wanted to address her communication difficulties before "things get worse" in her relationship.

Amy was cordial and pleasant to speak to at the beginning of treatment, but appeared very hesitant to explicitly discuss any difficulties or anxiety that she may have been experiencing. Frequently, when I would ask her if she experienced anxiety during a given situation, she would quickly deny experiencing anxiety and rationalize any pseudo-anxious behavior in which she engaged. For example, during the second intake session Amy was discussing a situation where she felt hesitant to talk to her father when she got home from work because she was "not sure if he would say hi or not." I asked if she noticed herself experiencing any anxiety as she was walking into her house and anticipating an "awkward" interaction with her father, and she quickly denied experiencing any anxiety, saying "I was just, you know, curious if I should ask him; I wasn’t anxious.”

Amy exhibited the tendency to minimize and downplay her difficulties throughout the first intake sessions and continued this pattern for much of treatment; there were numerous times during treatment where, after Amy reported experiencing certain anxiety symptoms on presession self-report measures, I would follow-up on Amy's indication of anxiety and she would say she misunderstood the question or she was "not really" anxious and she "did not know why" she reported anxiety symptoms.

\section{Diagnosis}

Amy presented for treatment with some symptoms of an anxiety disorder, including rumination, anticipatory anxiety, concentration difficulties and anxiety when talking to her father and boyfriend, and muscle soreness after worrying. While some of Amy's symptoms fall under the diagnosis of Generalized Anxiety Disorder, her anxiety did not occur in multiple situations and was not global enough to warrant a diagnosis of GAD. Due to the specific nature of Amy's anxiety, she was given a DSM-5 diagnosis of 300.00, Unspecified Anxiety Disorder. Amy's anxiety symptoms first began in middle school and persisted until the time of treatment.

\section{$\underline{\text { Strengths }}$}

Despite our treatment constituting Amy's first experience with therapy, and the anxiety she experienced by discussing her thoughts and feelings, she was remarkably committed to attending sessions and never missed a session. Additionally, though there were times where Amy felt anxiety after being asked to describe her experience, she was very willing to engage with the question, even if she was unsure of what to answer. Amy had a very positive 
relationship with her mother, saying that she felt like she could tell her mother "anything." Finally, Amy was readily able to engage with the interrelated cognitive, behavioral, and affective components of her communication difficulties and evidenced a strong ability to cognitively understand complex psychological phenomena.

\section{5.b. Amy's Case Formulation and Treatment Plan}

\section{Case Formulation: The Cyclical Maladaptive Pattern (CMP)}

Similar to the case conceptualization utilized in Beth's treatment, Amy's case conceptualization included the five pre-existing sections of a CMP, with the addition of a section of the conceptualization covering her pattern of attachment to pleasant experience and avoidance of unpleasant experience.

- $\quad$ Acts of the Self: Amy felt uncomfortable and anxious if she experienced others as cold or distant in relationships. During interactions with those who she "couldn't read," she preoccupied herself with trying to figure out what they want and what they're trying to communicate. When others would not engage in social interactions, Amy blamed herself for the lack of social interaction and felt that she had to "try harder."

- Expectations of Others' Reactions: Amy expected others to be hurt and upset if she expressed her dissatisfaction in relationships and more actively asked others to participate in relationships. She said she worried her father would be "devastated" if she asked him to be more participatory in their relationship and thought that she would "ruin" her relationship with her boss if she asked her boss to communicate in a more clear manner.

- $\quad$ Acts of Others Towards the Self: Amy’s father routinely did not engage with her when she came home from work and "rarely" asked her about her day. Additionally, when Amy spoke to her boyfriend about his lack of communication, he responded that he “didn’t know what to say” and was “frustrated” with Amy’s reaction to his communication style.

- $\quad$ Acts of the Self Toward the Self: Amy believed that her communication difficulties resulted in her "not caring enough" about the other to be able to "read" them. She saw herself as "not good enough" in relationships; were she more caring, more engaged, and more able to intuitively determine what the other wants or needs, she would not have had her interpersonal "difficulties."

- Therapist's Interactive Countertransference: In my work with Amy, I found myself frustrated at her intellectualization and reticence to engage in an emotional manner. During these times, I noticed myself withdrawing slightly, becoming less interested in the relationship, and expressing fewer of my reactions to what was occurring in the room. 
- $\quad$ Attachment/Aversion Patterns: When Amy experienced her unconscious feelings of sadness and fear during interpersonal interactions, she attempted to avoid these experiences through ruminative problem-solving. Amy experienced a few instances of this rumination producing effective solutions and attempted to recapture these feelings of efficacy through her ruminative avoidance patterns.

\section{$\underline{\text { Treatment Goals and Planned Phases of Treatment }}$}

The broad goals of Amy's treatment are similar to Beth's: the provision of new intrapersonal/interpersonal understanding and experiences in order to foster more adaptive behavior and interrupt Amy's CMP. I hoped to foster new intrapersonal experiences for Amy by encouraging her to sit with, rather than avoid, her affect, focusing particularly on affect that was attachment-related in nature. Amy frequently used various means, such as rumination, to avoid unconscious anxiety related to both her anger with her father and her fear of hurting her father; by aiding Amy in turning towards this experience, without trying to change it, her patterns of affective avoidance would be circumvented. The goal of providing Amy with new interpersonal understanding would play out simultaneously with her new interpersonal experiences. At the start of treatment, Amy knew that she didn't like how she and her father were interacting, but didn't know what her feelings these interactions engendered. Throughout treatment, I would attempt to foster new intrapersonal understanding through focusing on Amy's in-the-moment experience, placing particular emphasis on her experience during times of frustration in interpersonal settings.

Treatment would attempt to bring Amy new interpersonal insight through bringing Amy's attention to her interactional style and how this contributed to others reacting in ways Amy finds upsetting. Through discussions of her interactional style both in and out of therapy, I hoped to illustrate to Amy how her style of experiencing interpersonal frustration, blaming herself, and intellectualizing lead others to withdraw in relationships, further causing Amy to interpret events as a failure on her part. Coupled with her new interpersonal understanding, I would to provide new interpersonal experience by encouraging her to express her frustrations with me in session and, eventually, express her frustrations to her father. By giving voice to her previously unexpressed emotion, and my responding with encouragement and appreciation rather than hurt and anger, Amy would have the experience of the other engaging, rather than disengaging, when faced with her emotion. Over time, I hoped that this new experience would cause Amy to be more active and forward in relationships, leading others to engage more fully.

The four above-mentioned general treatment goals are reflected in a three-phase treatment model, described below:

\section{Phase 1 Treatment Goals}

- GOAL I: Orient Amy to the TLDP model; collaboratively explore and identify the sections of her CMP; discuss how her CMP is contributing to psychological distress. 
- GOAL II: Orient Amy to the aversion/attachment (A/AMCS) model; begin to explore Amy's orientation to her experience; identify initial patterns of avoidance and attachment.

\section{Phase 2 Treatment Goals}

- GOAL III: Introduce Amy to mindfulness practice via eight mindfulness training sessions immediately prior to therapy sessions; incorporate the practices of staying with experience and responding to emotion into therapy sessions; identify strategies for continuing mindfulness practice after formal training sessions are over.

- GOAL IV: Encourage Amy to express her affective and attachment-related experiences in therapy; begin to "sit with" aversive experience in session; examine Amy's momentto-moment experiences of interpersonal interaction within the therapy.

- GOAL V: Reduce Amy’s ruminative reaction when confronted with aversive experience; notice when this reaction is occurring in session and bring Amy's attention to her experience, rather than focusing on her judgments about her experience; encourage Amy to experiment with this alternative reaction to experience in her interactions with her father and boyfriend.

- GOAL VI: Explore attachment-related affect surrounding her father and boyfriend; identify how Amy's attachment-related fears arise in her relationships and prevent her from getting her needs met in relationships.

\section{$\underline{\text { Phase } 3 \text { Treatment Goals }}$}

- $\quad$ GOAL VII: Examine how Amy has attempted to express her needs to her father and boyfriend; explore attachment fears that have arisen in her experimentation with expressing her needs.

- GOAL VIII: Introduce the concept of skillful means; collaboratively identify situations in which Amy could apply skillful responses to interactions with her father and boyfriend; determine how more skillful responses to interpersonal situations could lead to Amy getting her needs met.

- GOAL IX: Generalize previously identified examples of Amy’s skillful means; encourage Amy's development of skillful responses and facilitate Amy' spontaneous generation of skillful responses in the moment; stress the principle that there is no "right" or "wrong” way to go about a situation, but more or less skillful strategies to get Amy's needs met and goals accomplished. 
Aversion/Attachment Model of Client Suffering: The Cases of "Beth" and "Amy" J. M. Samlin

Pragmatic Case Studies in Psychotherapy, http://pcsp.libraries.rutgers.edu

Volume 12, Module 4, Article 1, pp. 238-308, 12-16-16 [copyright by author]

- GOAL X: Consolidate Amy’s treatment gains and discuss how Amy could continue and maintain the skills and new ways of interacting with experience she has cultivated in treatment.

\section{6b. Amy's Course of Treatment}

Phase 1: Sessions 1-5

Before the first session of Amy's formal treatment, we met twice for two intake sessions. Similar to Beth's treatment, the two intake sessions focused primarily on information gathering, so I came into therapy having a general working knowledge of Amy's presenting problem and the history of her problem. Because of this, I was able to have here-and-now experiences as the focus of our sessions from the beginning, rather than spending the first portion of treatment collecting diagnostic and historical information. At the end of the two intake sessions, we agreed that treatment would consist of roughly 20 sessions, occurring over 5-6 months.

Amy spent much of sessions 1 and 2 talking about a new job opportunity and her nervousness at the prospect of telling her boss she would be leaving. During our conversations, I noticed what seemed to be attachment-related affect, but when I reflected potential attachmentrelated affect, such as wondering if Amy was nervous about her boss being disappointed in her for leaving, Amy responded intellectually with statements such as, "not really, I just have to get out of my head.”

Noticing this pattern, I focused on specific moments of anxiety that occurred at work the previous day. Amy and I went through the step-by-step process of how one internal event (thought, feeling, expectation, etc.) led to another and ended with Amy feeling stuck and nervous, similar to the "chain analysis" (Linehan, 1993) process done with Beth. Amy seemed to be more comfortable engaging with this concrete level of discussion and was able to identify affect she was experiencing during the course of her day. Amy ended this discussion by saying she tries to "figure out stuff to do to fix the situation" when she feels anxious. This statement indicated an important piece of Amy’s Cyclical Maladaptive Pattern (CMP): she avoided aversive experience through trying to problem solve and "fix" things.

In the second session, Amy talked about her father "staying to himself" the past weekend and said she worried that he was upset when he was by himself. She went on to say that she was particularly worried her father was upset when he was by himself because, "I don't spend enough time with him or I don't talk to him more.” I was struck by the very real and very present attachment fear implied in this statement: if my father isn't engaged he is sad, and if he's sad, it's because I'm not good enough.

The above statement provided a great deal of insight into Amy’s CMP, which was more fully explored in session 3. Amy reported that she got a new job and was faced with the prospect of telling her boss she was leaving. While examining her anxiety over this prospect, Amy said that she was nervous about telling her boss because she didn't want to "burn any bridges" by leaving her job (despite giving a month’s notice). She was worried that the ending of her job 
would "ruin" the relationship between her and her boss, which would negatively affect the search for future jobs.

In the course of our conversation I noticed an attachment-related fear that seemed to be playing out with her boss: Amy worried that people would leave her if she says or does things they don't like. I reflected to Amy that it must be scary to feel that she might lose a relationship if she says something the other person doesn't like and she said that she just had to "figure out what to say" to her boss and "everything would be fine."

At this point in the session, I began discussing the concept of the second dart and how suffering can be created by moving away from experience. I identified how Amy had been moving away from her nervousness around her boss by trying to figure out the "perfect thing to say" and we talked about how this made her "stressed" throughout the day.

I then expanded upon my explanation of the second dart and oriented Amy to the A/AMCS. I chose to shift the conversation from our discussion of her anxiety to an orientation of the A/AMCS for two main reasons. First, I felt that we had adequately established what internal states Amy was experiencing in relation to leaving her job and could discuss and reference her internal experience. Second, Amy was directly identifying what ways she moves away from her experience (trying to figure out the "perfect" thing to say). Directly following this was a brief explanation of what I saw as Amy's CMP leading to her interpersonal distress. As we discussed her CMP, Amy readily acknowledged that she was "really unhappy" with her relationships and asked how she could "get better at having relationships.” I began explaining how mindfulness meditation can help us move towards experience and engage in relationships; we set our first mindfulness pre-treatment for session 5 .

During session 4, in response to my asking how she and her father were doing, Amy said that she felt like she "should say 'thank you' to him more." When I asked what she would be thanking him for, Amy visibly slumped in her chair and said, "I don't know. I'm not really sure what he needs." I reflected what I saw as her frustration and sadness around not being sure how to make her father engage and she said she wondered if he felt frustrated with her, as well. Amy began discussing her feeling that she "should be doing something to make the situation better". I brought her attention to her seemingly taking on the majority of the responsibility for improving the relationship and, keeping in mind Amy's tendency to take on the blame for her relationship with her father, I reflected:

Jason: I can really appreciate this tendency that you have to try to figure out what's going on with you and your dad. It just seems like there's so much frustration there and I can imagine that you trying to reason your way into a better relationship has come from a lifetime of trying to figure out why it's not working.

Amy: Deep down, I think I'm just mad at him. It's like he doesn't try to meet people's basic needs sometimes. 
Through this conversation, Amy was able to access powerful affect towards her father for the first time in treatment. For the remainder of the session, we processed Amy's anger and frustration that her father wasn't meeting her "basic needs" for warmth and affection. During this conversation, I noticed myself becoming more engaged and interested and felt Amy become more invested in the conversation than she had been at any point previously in treatment.

Session 5 was supposed to be the first time we had a mindfulness pre-treatment session, but Amy arrived to session twenty minutes late because of car troubles and we agreed to start the mindfulness sessions the following week. Amy came to session extremely apologetic for her tardiness and said that she felt "really stressed" about being late to session.

It seemed to me that Amy's lateness gave us a wonderful opportunity to examine her inthe-moment fear of lateness and my disappointment. After asking Amy what worried her about being late, and receiving largely intellectualized answers, I asked Amy what she thought my reaction would be to her lateness; I thought that shifting the focus to our relationship might better get at Amy's avoided affect. Amy said that "I didn't know what your reaction would be, so that kind of not knowing makes me stressed.” I didn't realize it at the time, but her experience of anxiety when she was unsure of what my reaction would be was an almost direct mirroring of her anxiety around not knowing how her father would react to things.

We continued our examination of Amy's reaction to her being late and, towards the middle of the session, I asked her what it was like to experience her anxiety, rather than what she associated with her anxiety; again, I was attempting to circumvent her proclivity for intellectualization by probing around her felt experience rather than her thoughts about her experience. Upon being asked this question, it seemed that Amy was becoming more frustrated and said, "I don't know how to describe it. Can you give me an example of how to describe it?" After this statement, I was struck by Amy's extreme, almost pre-verbal difficulty in turning towards her felt experience and, rather than explore her difficulty, I chose to talk about my experience of her anxiety as a way to model the discussion of affective experience.

While Amy's frustration seemed to dissipate after this, she was still predominantly engaging with her anxiety in an intellectualized manner. At the end of the session, while discussing her frustration with taking on too many tasks, Amy asked, "Do I need to learn how to manage my time better? Do I need to say ‘no’ more?” Wanting to validate her experience without engaging in affective avoidance, I chose to not answer her question, but validated her difficulty by saying that "it must be so incredibly tough to manage things when you feel like other people will think negatively of you; I can imagine myself feeling pretty anxious around this stuff if I feel like me dropping the ball on anything will mean that I'm just not good enough.” Despite my attempt at validation, though, Amy continued to wonder if her problems are "just that I can’t manage my time.”

\section{Phase 2: Sessions 6-13}

Prior to session 6, Amy and I met for the first of 8 mindfulness pre-session trainings. Each session lasted for 30-minutes and was immediately followed by our therapy session. For a summary of Amy's mindfulness practice sessions, see Table 14. Amy began session 6 by talking 
about an incident that occurred over the past week where her father didn't say hello to her when she came home from work. She said that she became "really frustrated" when he didn't say hello to her and thought, "I don't want this. What did I do to make him mad?” She appeared to be bringing a great deal of attachment-related affect into the session and seemed on the verge of either moving toward this affect or continuing to intellectualizing her attachment fears.

In order to aid her in processing this affect in a comfortable way, we engaged in another chain analysis type of exercise where we went through her step-by-step experience of her father not saying hello to her. As the exercise concluded and Amy was discussing self-critical thoughts and feelings of frustration towards her father, I asked why she didn't communicate her feelings to her father. She said that she worried that her disappointment would "really upset" her father and she didn't want to cause him pain. Throughout this discussion, I tried to encourage Amy to stay with her affect by making reflective comments focused on her affect such as, "I could imagine it would feel scary to disappoint him." While Amy was able to discuss her fears of disappointing her father for a few minutes, she quickly began intellectualizing and talking about how "parents should tell their children what they're feeling."

Between sessions 7 and 8, Amy reported that her then-boyfriend, who was African American, had racist comments directed at him at a family gathering held at Amy's house. She said that he was "understandably, really upset" and left the party soon after the comments were made. Because of this, session 8 mainly consisted of processing Amy's and her boyfriend's reactions to the racist comments. While there were opportunities in session 8 to bring Amy's attention to the avoidance of experience, I chose to focus on validating Amy's frustration with her family and aid her in processing her anger, frustration, and worry.

Session 9 began with Amy saying that she and her boyfriend had been "uncomfortable" with each other since her family gathering. She said that she had "figured out" why her boyfriend didn't talk about his emotions surrounding the situation and talked about how his family of origin never spoke about their feelings. At the end of Amy's explanation for her boyfriend's actions, though, she was left with feeling like he was "still mad" at her and said, "I'm not sure what he's looking for." I then began discussing how Amy seemed to intellectualize when she experiences anxiety in a relationship:

Jason: It seems like you try really hard to figure out what you did wrong when someone you have a relationship with doesn't really give you an idea of what they're thinking or feeling. It's almost as if you're never really sure what they want.

Amy: It does make me really insecure.

Jason: It also doesn't really let you get your needs met. If you're so busy trying to figure out the other person, you're not really spending any time figuring out what you want.

After this exchange, I shifted the conversation slightly to focus on what she wanted out of the relationship and how she might have gone about getting those need met. I wanted to focus more on Amy's needs and desires for two reasons. First, I thought that settling on Amy's attachment needs might serve to circumvent her intellectualization and re-orient her to her 
Pragmatic Case Studies in Psychotherapy, http://pcsp.libraries.rutgers.edu

Volume 12, Module 4, Article 1, pp. 238-308, 12-16-16 [copyright by author]

internal experience. Second, this focus on Amy's needs would further act as an affective exposure, continuing the process of Amy sitting with previously unrecognized affect. Amy was hesitant to engage with this process, frequently saying that she was unsure of what she wanted and she wasn't clear what I was looking for her to say. I took her hesitance as a sign that she was coming up against her "upper limit" of her affective exposure and again shifted focus slightly:

Jason: What would you want to tell your boyfriend if you could tell him what was so frustrating?

Amy: It's like, it’s like I feel like I can't rely on you, like you don’t really care about what's going on.

Amy appeared to be moving very close to her experience with her father ("It's like you really don't care”), but said the above with the same businesslike, even affect that was predominant in treatment. I asked what she thought was preventing her from saying this to her boyfriend or father. She said that she is "never sure when would be the right time," and then began discussing the logistical issues of communicating her needs. At the end of the session, Amy said that she felt like she was unsure of what to do because "I've tried to pay attention to my feelings, but they're still there and I still can’t talk to my boyfriend or dad.”

After this, the focus of therapy began to shift focus towards Amy's frustration at myself and the treatment. In session 10, Amy spoke about her frustration with some of the mindfulness practices such as the body scan, saying that they “weren't working” for her and she didn't feel helped by the mindfulness practices. As Amy was expressing her frustration, I chose to validate this affect and explore her experience of frustration at the nature of our treatment, rather than focus on her reluctance to practice the mindfulness exercises.

This represented a decision point that would play out over the next four sessions. I hoped that by encouraging and reflecting her expression of frustration I would both reinforce her expression of affect in therapy and provide her with an alternate interpersonal experience; rather than responding in the expected, feared way of hurt and rejection, I responded with openness, appreciation, and encouragement.

Amy continued to appear nonplussed and uninterested in my interventions during session 11. During the course of a discussion around Amy's fear that her boyfriend could be happy with another woman, I linked this fear with Amy's reticence to have a discussion with her boyfriend in which she communicated that she is unhappy with the relationship. When I said this, Amy appeared slightly annoyed and said, "Okay, this is here, so now what? Do I just have the conversation with him even though I'm scared and I don't want to?”

I mentioned that it seemed like Amy was trying to "do" a lot, without much time for letting the emotion be there and Amy said that she had "no idea how not to try and do something when I need to do something." I suggested that we do an exercise that centered on bringing awareness to emotion, and led her in a brief, 3-minute mindfulness of emotions exercise. This was the first time that I had explicitly incorporated formal mindfulness practice into a therapy 
session, but I felt that, rather than engaging in an intellectual discussion that moved her away from emotions, doing a brief mindfulness practice could enable her to sit with her experience.

After our brief practice, Amy said she “didn’t feel or notice anything.” She seemed to be becoming more frustrated by my questions and I asked her what it was like when I asked her about her experience after a mindfulness practice. She said that "most of the time, I'm not sure what you're looking for me to say since I don't feel or think anything.” At the end of this session, it seemed apparent that Amy was frustrated by our back and forth of me asking her experience and her not knowing what to say; I also found myself feeling frustrated at the seeming disconnect between Amy and myself.

Amy's frustration to a head in session 12 when, following a short silence at the beginning of the session, I asked what Amy was "up to" during the silence. She said that she was feeling "annoyed because nothing's bothering me and you keep asking me what's going on." This was the first time that Amy explicitly communicated her frustration or annoyance towards me, and I thought that the situation presented a fantastic opportunity to provide Amy with the experience of expressing interpersonal frustration in a safe, encouraging environment.

As Amy was expressing her frustration at my questioning style, I asked her what had prevented her from expressing her frustration, assuming that her reasoning for not communicating her experience to me was similar to her reasoning for not communicating her experience to her father or boyfriend. Amy said that she didn't want to express her frustration towards me because "it would be rude," and "not appropriate" to the setting. I understood this as a method of disengagement similar to what she had said in the past about her father ("I can never find a time to talk to him") and asked what she imagined herself saying to me, again encouraging her to express her frustration:

Amy: I just want to say, “That’s not what's happening to me, you're going too far. This isn't fun anymore.”

Jason: So maybe I'm missing the mark on some of this stuff.

Amy: It's like, I don’t like it when you tell me what my feelings are.

I expressed my appreciation that Amy was expressing her frustration, to which she replied that it was "really uncomfortable" for her to say she was frustrated. She said that she was "even more frustrated" because she can't express herself to her father and boyfriend. I said that I wondered if being polite and cordial “wasn’t doing more harm than good,” and we ended the session talking about how expressing her frustration towards me increased the likelihood that I would be attentive to her needs and experience in the future.

At the end of session 12 I found myself slightly discouraged and worried that, for all of our talk about the benefits of expressing emotion, Amy wasn't having the experience of being heard and validated after communicating her experience. Because of this, I was very pleasantly surprised when, during session 13, Amy reported that she had had a "really blunt" discussion with her boyfriend, during which she expressed her frustration about their relationship. Amy 
said that she “didn't want to talk about it, but I knew that moving away from it wasn't going to do me any good." The result of that conversation was Amy and her boyfriend "taking a break" and, while Amy wasn't sure if the relationship was going to continue, she said that, "It felt good after, knowing that I put it out there and something happened.”

\section{Phase 3: Sessions 14-20}

Amy began session 14 by talking about the possibility that she could still be "friendly" with her now ex-boyfriend. She spent of the beginning of the session reasoning out what she "should" have been doing and would then give reasons as to why she was unable to do anything that would make her feel "anything but in a weird place” with her ex-boyfriend.

Given that Amy had just finished the portion of treatment which included active mindfulness practice, I thought it would be appropriate to intervene in a way that would create purposeful activity rather than continue to encourage Amy to be with her experience. This reasoning led me to introduce the concept of Skillful Means as a way to enable Amy to respond to her internal experience with skillful action rather than intellectualization and rumination.

I framed Skillful Means as a way to "engage with what's going on in a way that still lets you accomplish what you want, while helping you to feel comfortable with both your experience and what you're doing in the situation.” Amy responded that, "I don't do things that might make me feel better because I just run through all the scenarios in my head, it doesn't seem like that would be too skillful." This led us into having a discussion around how Amy could "be okay" with her decisions. At the end of the discussion she said, "I feel like this is making me less guilty over what I want to do; it's like it's okay with me having my experience because trying to reason my way out of it would make it so much worse.”

Although my intention with the introduction of Skillful Means was to explore with Amy behaviors that would reduce her suffering, our discussions generally led to Amy talking about what is preventing her from engaging in Skillful Means. Amy continued to notice her habit of trying to "figure out" others in conversation and was able to verbalize somewhat how this tendency might limit her ability to connect with present experience. We examined her tendency towards intellectualization and rationalization, and Amy discussed how she experienced emotions as requiring management so that "things don’t get out of control.”

Throughout sessions 15 and 16 I tried to highlight the disparities between Amy's behaviors and desired outcome; though Amy was interested in engaging more deeply with her father, her inclination towards trying to "figure out," rather than experience emotion, was serving to further distance her from her father. I felt that these conversations were worthwhile and still served the aim of this intervention through the examination and challenging of Amy's defenses; Amy was beginning to identify how her behavior was unskillful and to move up against what was preventing more skillful behavior.

In session 17 Amy began by saying that she has been trying to "move away from reasoning things out and just experience what's going on.” I experienced this as a big shift from her previous intellectualization and rationalization of her affect. Amy said that she experienced a 
situation during the previous week where she was, "just frustrated and being okay with being frustrated." She explained that over the past week her father made plans for her and her parents without telling Amy, which forced her to cancel previously scheduled plans she had with friends. Amy said that she was "really pissed off" and "felt all the frustration I had with him, but for some reason I kept not being able to tell him.” Given that Amy appeared to be more directly recognizing her experience, I engaged more directly with her "roadblock":

J: What would a skillful way to tell him look like?

A: I guess I'd just say that I was frustrated and I wish he wouldn’t just make plans.

J: So what would that look like? If you were talking to your dad right now, what would you say?

A: Hey, when you're making plans, tell me. Don't just tell mom and assume I'll figure it out, tell me. It's really frustrating when you just do stuff and expect me to disrupt my plans to go along.

Through this role play, Amy was able to express both her frustration with her father and engage in the situation in a way that would increase the likelihood of her needs getting met; she might not have to disrupt future plans to accommodate her father. Following this exchange, Amy said that, "It would feel good to say that, but I just don't know how I can." I encouraged her to "drop into what's going on now," and she said that she was worried that she "wouldn't get anything back from him" and he would be "completely flat” in his response. Our discussion shifted to Amy's sadness at "just not expecting anything” from her father, and towards the end of the session Amy reflected, “It's like I'm spinning my wheels, part of me knows that there's only so much I can do and part of me knows that I just need to work harder at it.”

Between sessions 17 and 18 the father of one of Amy's best friends passed away suddenly. Amy said that, in addition to her feeling "really sad" for her friend, the man's death was a "huge wake-up call” for Amy to have a better relationship with her father. She said, "I guess I've just been thinking that I want things to be how I want them to be, not how they are now. I want to have an actual relationship with my dad." Sensing that Amy was at a point where she was ready to engage in action with her father, and bearing in mind that treatment was coming to a close, I brought up the fact that we had only three sessions of treatment left and asked if Amy was interested in using the final sessions to focus on her acting on her desire to have a different relationship with her father. Amy said that she wanted to "take a risk" with her father during the therapy "so we could talk about it together."

I was struck in this moment how connected I felt to Amy when she was discussing her desire to speak to her father. That is to say, for the previous few sessions I'd felt more like an observer than a participant in treatment; I would ask questions and offer my take on things, but Amy seemed to be pursuing a different route, particularly when she would intellectualize about "practical” reasons she was unable to speak to her father. My experience of a shift in our relationship indicated to me that Amy was engaging with me in a different, more open manner. As the session progressed, I suggested, "Why don’t we skip past the things you'd say to your 
father, you know what to say, why don't we focus on how you actually feel about your dad, how you want your relationship with him to be." Amy said that she had "always wanted to be daddy's little girl, but I was never able to have a relationship like that.” Throughout the conversation, I attempted to redirect Amy to her experience of her sadness and disappointment, but also her hope for a better relationship with her father.

In session 19, Amy said that she was “pissed” that she wasn't able to speak to her father during the previous week. She said that she was "feeling kind of envious" towards her friend because her friend "had a relationship where she could actually talk to her father.” Amy's description of her frustration surrounding her communication difficulties with her father, and later her analysis of the situational factors that prevented her from speaking to her father, felt different to me that session than in previous sessions. Whereas previously I experienced these types of discussions as intellectualized and defended, there was a sadder, more urgent quality about Amy's description of her difficulties this session. Attempting to slow down the session and create space for Amy's powerful affect, I asked her if there was anything she regretted about her relationship with her father. When I asked this question, Amy stopped speaking, looked at the floor, and began crying softly. I started to reflect what I noticed in the room:

J: So there's some real powerful stuff here, what we've been talking about. Something we were just talking about really struck you.

A: I'm thinking about wanting a relationship with my dad that I don't have. I don't know why it's not there and I want it to be. I feel like it's my fault, I feel like I'm the one who's not trying hard enough.

J: So there's a lot of responsibility that you're taking on with this. I wonder if I've been complicit in that a little bit in here. We've been working around how you can really connect with your dad and steps you could take to change the relationship, but I wonder if something's been left behind in the process. This hurts. It hurts not having your dad in your life.

A: I'm feeling like I'm not a good daughter.

$\mathrm{J}$ : Yeah, and this stuff is really hard to sit with. I'm sort of feeling like all of this planning and preparation that we've been doing has made it even harder to sit with. Does that match with your experience?

A: Yeah, I guess. When I've felt the sadness instead of trying to fix it, I've definitely gotten more done and been less anxious.

This was the first time in the entire treatment that Amy was tearful, and I hoped that joining with the part of her that was experiencing sadness and pushing back against our "doing" would better enable her to experience and process this sadness. Further, this conversation shifted the focus in the room back to Amy's experience without trying to mobilize that experience for any purpose; creating space in the room for Amy to experience her sadness and cry opened both of us up to the possibility that we had been "doing” too much. 
Pragmatic Case Studies in Psychotherapy, http://pcsp.libraries.rutgers.edu

Volume 12, Module 4, Article 1, pp. 238-308, 12-16-16 [copyright by author]

Going into our final session (\#20), I was curious about Amy’s reaction to her increased expression of affect; I was unsure if she would react to her experience in session 19 by continuing to turn towards her affect or by becoming more closed off and defended.

Amy began session 20 by saying that she didn’t speak to her father over the week because she "couldn't find the time." She spoke about not talking to her father with an air of nonchalance, saying, "I guess it's not that big of a deal. I'll find a time eventually, whatever.” It seemed to me that Amy was reacting to the previous session with her seeming apathy towards speaking to her father, and I chose not to pursue the contrast between her presentation in this session and the previous week. Amy went on to talk about her frustration that she didn't talk about her father and said, "I know it’s just on me to do it, I’ll just have to try harder."

I asked if she felt frustrated that the therapy was ending, hoping to elicit some of the frustration, possibly towards me, that I felt in the room. Amy shrugged and said, "Not really, I guess I just got out as much as I could.” The discussion moved towards how Amy could continue the work of therapy after treatment was over and Amy said that "I guess I just need to be with myself more." I suggested that she consider continuing therapy after we end, and she agreed to consider it after "taking a break."

\section{THERAPY MONITORING AND USE OF FEEDBACK INFORMATION}

Therapy monitoring was utilized throughout the course of treatment through both supervision and the utilization of self-report measures. While engaged in treatment with Amy and Beth I was receiving supervision from Dr. Seth Warren, a licensed clinical psychologist who had a great deal of experience in both short-term dynamic psychotherapy and mindfulness meditation.

During supervision, we reviewed treatment sessions, identified emerging themes, and developed intervention strategies centered around treatment goals. Supervision was particularly valuable in examining transference and countertransference reactions that were occurring in treatment. I frequently discussed my reactions with my supervisor, and he was extremely helpful in pointing out ways countertransference reactions could be used effectively in treatment. Additionally, Dr. Warren would review DVD recordings of my sessions every week. Supervision served both to enhance and challenge my conceptualization and treatment of Beth and Amy, as well as offer me a space to process and focus my own reactions to treatment.

Both Beth's and Amy’s treatments were continually assessed using self-report measures. For a more thorough review of the self-report measures used in each case, see the assessment Sections, 4a and 4b, and Tables 2-7 and 9-13. All measures were completed prior to therapy sessions. Self-report measures were used as part of supervision to provide real-time feedback to myself and my supervisor, and were brought up in session when appropriate. (The one exception was that my supervisor and I did not review the bi-weekly administrations of the Working Alliance Inventory due to the potentially confounding effects that would occur if I saw the clients' reports on their views on our relationship.) The completion of the other self-report 
measures both informed me as to the progress of therapy and served to enhance Beth and Amy's understandings of their experience.

\title{
8. CONCLUDING EVALUATION OF THE THERAPIES' PROCESS AND OUTCOMES
}

\author{
The Outcome of Beth's Therapy
}

As the quantitative and qualitative data below indicate, Beth had a very favorable response to treatment. Beth appeared to be engaged and interested to treatment, and I believe that her willingness to "put in the work" of therapy is reflected in her improvement over the course of treatment.

\section{Quantitative Results}

Table 2 presents Beth's scores on the OQ-45. Her pre-treatment scores on the Total, Symptom Distress, Interpersonal Relations, and Social Role scales all fall above the clinical cutoff, indicating that Beth was experiencing distress in all of these areas. Her post-treatment scores, though, fall below the clinical cut-offs on all symptom scales. Additionally, on scales measuring total distress, symptom distress, and social role, her scores were reduced by a clinically significant amount, as measured by the Reliable Change Index (RCI; Jacobson \& Truax, 1991). Though Beth's scores on the Interpersonal Relations subscale were reduced to sub-clinical levels post treatment, her scores did not constitute "reliable change" as measured by the RCI. While Beth noted reductions in feelings of loneliness and improved perceptions of her relationships, there were still portions of her romantic relationship (e.g., sexual relations) which she felt were not satisfactory.

Table 3 presents Beth's scores on the BDI-II. Her pre-treatment scores were indicative of severe depression, which lasted several sessions into treatment. Over the course of treatment, Beth's scores reduced to those indicating minimal depression and she was able to maintain these scores for the final five weeks of treatment.

Table 4. presents Beth's scores on the BAI. Her pre-treatment scores indicated severe anxiety and, after treatment, her scores indicated minimal anxiety. Similar to her scores on the BDI-II, Beth reported scores indicating minimal anxiety for the final seven sessions.

Table 5 presents Beth's scores on the WAI. As measured by the Reliable Change Index, her scores indicated that on all four measures, Beth perceived her relationship with her therapist to become more positive to a statistically significant degree over the course of therapy.

Table 6 presents Beth's scores on the MAAS. Her scores indicate that she was more liable - to a statically significant degree on the RCI-to experience openness to new experience, reduced judgment of herself and her experiences, and increased awareness after the conclusion of treatment. 
Table 7 presents Beth's scores on the NAS. While a reliable change index calculation was not possible due to the lack of applied research on the NAS, Beth's responses on pre and post-treatment administrations indicate that she was more likely to allow pleasant experiences to pass, less likely to avoid negative experiences and run on "automatic pilot," and more likely to accept the moment-to-moment flow of her experiences after the conclusion of treatment.

Beth's scores on both the MAAS and the NAS indicate that she underwent changes in her behavioral and cognitive responses to experiences that are in line with the goals of the A/AMCS. Her responses on the MAAS indicate that she internalized the concepts and practices of mindfulness meditation such that she was able to bring an openness to her experience that was not previously present in her life. Further, her scores on the NAS indicate that, by the end of treatment, Beth was less likely to try to purposely avoid unpleasant experience and prolong positive experience. Both of these changes indicate a shift in Beth's engagement with her life from reactivity to responsiveness, which was one of the primary aims of the A/AMCS.

\section{$\underline{\text { Qualitative Results }}$}

As illustrated in Section 6a, on Beth's course of treatment, Beth and I reviewed her treatment gains in the final phase of treatment. The following reflects a summary of Beth's treatment gains:

- Beth experienced dramatically reduced depressive symptoms, as reflected by her scores on the BDI and behavioral changes. She had improved mood, increased interest in her life and those around her, dramatically reduced self-hate, and improved sleep and eating habits. Additionally, she felt content with how she engaged in her life.

- Beth was able to completely abstain from non-suicidal self-injury for the majority of treatment. Over the course of treatment much of her urges to self-harm reduced and, by the end of treatment, when she experienced an urge to self-harm she was able to notice the urge without engaging in self-harm behavior.

- Over the course of treatment, Beth was able to notice her experience of things without avoiding aversive experience and chasing after positive experience. Beth evidenced the ability to act with equanimity and have acceptance for whatever experience she might be having.

- Beth was able to express her experience and emotions to both her boyfriend and mother instead of "holding in" her emotions and then "exploding." By treatment's end, she had fewer outbursts and fights with both her boyfriend and mother and was able to engage both of them in meaningful conversation around her experience.

- Beth was able to adapt skillfully to the demands of a specific situation rather than become stuck in how a situation "should" be. Because of this, she was better able to get her needs met by those around her. 
Pragmatic Case Studies in Psychotherapy, http://pcsp.libraries.rutgers.edu

Volume 12, Module 4, Article 1, pp. 238-308, 12-16-16 [copyright by author]

- As a result, Beth's relationship with both her boyfriend and mother greatly improved by the end of treatment. She was enjoying her time spent with her boyfriend more and felt that he was providing her with the support and care that she desired.

\section{Beth's Results in Context of the Original Treatment Plan}

Based upon the quantitative and qualitative results of Beth's treatment, she was able to meet the treatment goals outlined in Section 5a, Beth's Case Formulation and Treatment Plan. Beth certainly seemed to experience improvement in her overall functioning, as indicated both by her reduction in depressive symptoms and her interpersonal improvement. Additionally, Beth was able to understand and internalize the ways in which she was avoiding negative experience and how this process contributed to her suffering. By the end of treatment, she felt that she was more fully immersed in her life and was no longer getting "battered by the waves" of her experience. Through our work together, Beth was able to take a more active role in her life and reduce suffering.

\section{The Outcome of Amy's Therapy}

Whereas Beth's treatment represented a clear-cut instance of success, the results of Amy's treatment provided more mixed results. As is reflected in both her quantitative scores and qualitative observations, she made some treatment gains, but ultimately did not appear to achieve the interpersonal change she sought.

\section{Quantitative Results}

Table 9 presents Amy's scores on the OQ-45. None of Amy's pre-treatment scores on any of the four subscales of functioning were above the clinical cut-offs as outlined by Lambert et al. (2004). In fact, only one score on any of the subscales over the entire course of treatment ever rose above a clinical cut-off (Social Role, session 19). Despite her scores not indicating a clinically significant impairment in functioning, Amy's reduction in scores on the Total Symptom, Symptom Distress, and Interpersonal Relations subscales between the first and last session met statistical significance according to the RCI.

Table 10 presents Amy's scores on the BAI. In spite of the fact that Amy had a diagnosis of Anxiety Disorder NOS, both her pre- and post-treatment BAI scores indicated minimal levels of anxiety. In fact, Amy only reported scores above minimal anxiety one week during treatment. Given that the BAI predominantly measures physiological symptoms of anxiety, it seems that the BAI did not pick up the anxiety associated with Amy's diagnosis because Amy's anxiety was much more intellectualized in nature and not physiologically experienced.

Table 11 presents Amy's scores on the WAI. Her scores indicate that she saw herself and the therapist differing on the therapeutic task and goals of treatment as the therapy progressed. Of note is that her scores on the measure of therapist-client Bond fell over the course of treatment to the extent that this reduction met criteria for statistical significance as measured by the RCI. This may be reflective of the frustration and annoyance Amy felt towards the therapist in the final phase of treatment. 
Pragmatic Case Studies in Psychotherapy, http://pcsp.libraries.rutgers.edu

Volume 12, Module 4, Article 1, pp. 238-308, 12-16-16 [copyright by author]

Table 12 presents Amy's scores on the MAAS; she achieved the same score at both preand post-treatment. Of note is that this score does not seem to be reflective of the therapist's observations of Amy in the beginning of treatment, where the therapist observed Amy to be less mindfully aware than at termination. Table 13 presents Amy's scores on the NAS. Her pretreatment scores were slightly higher than her post-treatment scores, again differing from both Amy's in-session self-report and the therapist's observations.

\section{Qualitative Results}

Similar to Beth's treatment, Amy and I reviewed her treatment gains during the final phase of treatment. The following reflects a summary of Amy’s treatment gains:

- Over the course of treatment, Amy experienced a reduction in her anticipatory anxiety in situations which previously were anxiety producing, such as having "uncomfortable" conversations at work or telling her friends that she was not able to get together with them.

- Amy reported an increased openness to experience. She was able to notice her experience rather than ruminate about situations that had occurred.

- As Amy was experiencing difficulty in her relationship with her ex-boyfriend, she was able to recognize and advocate for her needs with him. Amy recognized her unhappiness in the relationship and was able to determine what her attachment needs were and how to get them met.

- Relatedly, Amy utilized the concept of Skillful Means to determine how best to act in a situation. Taking an interpersonal framework, Amy was able to generalize her process of skillful action to situations outside of her relationship with her boyfriend.

- Towards the end of therapy, Amy was able to express her frustration at her relationship with her father in a deeper manner than the annoyance she reported at the beginning of treatment. Amy reported feeling sad about her difficulty to form a meaningful relationship with her father, saying, "I feel like I'm grieving the relationship I never had." Amy's affect related to her relationship with her father shifted from constriction and annoyance to expansiveness, sadness, and grief.

\section{Amy's Results in Context of the Original Treatment Plan}

Based upon the qualitative and quantitative results described above, Amy was able to meet many of the treatment goals outlined in Section 5b, Amy's Case Formulation and Treatment Plan. Amy presented for treatment with the hopes of examining her relationships with the men in her life and determining why she had difficulty communicating with her father and boyfriend. As her quantitative data on the OQ-45 in Table 9 suggest, she presented with some overall distress at the beginning of treatment, although the level of her reported symptoms was not at a clinical level. Even so, she was able to reduce her overall distress over the course of treatment to 
a statistically significant degree. Additionally, while she was able to effectively examine her relationships with the important men in her life, and the attachment patterns behind those relationships, this understanding produced limited, although important, behavioral change. For example, she was effectively able to advocate for herself and communicate her needs to her exboyfriend, but at the conclusion of treatment she could not yet communicate her attachment needs to her father. Amy's treatment, then, could be viewed as a qualified success in that she was able to gain new interpersonal and intrapersonal understanding, as well as demonstrate an improved ability to sit with difficult experience, but the interpersonal behavioral changes she accomplished were somewhat limited in scope.

\section{Discussion of Broader Issues Raised by Beth's and Amy's Treatments}

\section{Comparing and Contrasting Treatments}

Beth's and Amy's treatments represent examples of a very successful and moderately successful therapy. Indeed, while Amy experienced moderate treatment gains, Beth reported experiencing a profound shift in her cognitive, behavioral, and interpersonal functioning. It can be informative to explore some explanations of these different results.

Background in psychotherapy. The first difference of note between Beth and Amy was that Beth had a long history of psychotherapy whereas this was Amy's first experience of psychotherapy. It is possible that Beth's familiarity with the process of psychotherapy prepared her for the type of intensive intrapersonal and interpersonal self-reflection and analysis that took place in treatment. On a more basic level, Beth appeared comfortable reporting her experience and engaging in basic therapeutic processes like talking about affect. Much of the first and second phases of Amy's treatment seemed to involve her acclimating to my asking her questions about her experience. It was not until well into Phase 3 of treatment that I had a sense of Amy feeling comfortable reporting her experience, and even then I sometimes felt as though I had to “drag” her experience out. Reflecting on this difference in basic comfort level in treatment, I'm reminded of one of Levensons's (2010) inclusion criteria of TLDP, which suggests that potential clients be willing and able to examine their difficulties through an interpersonal lens. After concluding treatment with Amy, I am unsure as to her readiness to truly examine her difficulties in an affectively stimulating, interpersonal way.

Severity of the presenting problem. Another factor potentially influencing the clients' experiences in treatment is severity of presenting problem. Whereas Amy's initial self-reported difficulties (although potentially minimized) indicate that she was generally functioning well despite her interpersonal distress, Beth's initial presentation was one of intense suffering and pathology, with a Total OQ-45 score of 107. In a sense, then, Beth's treatment gains could appear so dramatic because she was experiencing such difficulty prior to treatment; while Amy's gains were smaller in comparison because she was faced with a relatively small impairment at the beginning of therapy, as reflected in a Total sub-clinical OQ-45 score of 51. All in all, while there can be a discrepancy between publicly admitted distress on the OQ-45 and actual distress, the initial OQ-45 scores did reflect each client's ability to publicly communicate distress, a characteristic that is important in facilitating effective psychotherapy. 
Responsiveness to the mindfulness practice sessions. While both Beth and Amy underwent the same structured mindfulness practice sessions, they responded to the sessions rather differently. Beth appeared engaged during the practice sessions and, though she engaged in limited formal practice outside of the sessions, she frequently utilized informal mindfulness practice, as well as the Three-Minute Breathing Space exercise, outside of the practice sessions. By the end of the practice sessions, Beth seemed to be willing to try to infuse her practice into her life; she frequently engaged in a few minutes of mindful breathing immediately before work and routinely did "informal” practices such as mindful driving and mindful dog walking. Beth's engagement with mindfulness outside of the practice sessions was reflected in the practice sessions in her willingness to notice her experience and explore uncomfortable affect.

Though Amy engaged in a roughly similar amount of out-of-session formal mindfulness practice as Beth, her experience of the practice was very different. When Amy practiced outside the practice sessions, she frequently felt like she was not "doing it right" and had trouble finding a time and place in which she was comfortable practicing. Whereas Beth, who also experienced some difficulty engaging in formal practice out of session, turned to informal practices, Amy did not engage in any other form of practice. I particularly noticed the effects of Amy's lack of practice during our therapy sessions when I would try to bring our attention to uncomfortable experiences or feeling states that came up during session. Amy seemed hesitant to move into these spaces and, while she seemed to have an intellectual understanding of the mindfulness concepts that could have aided us when exploring uncomfortable affect, I think her lack of experiential understanding of these concepts reduced her willingness to more fully turn towards her experience in session.

The question could be raised, then, as to why the formal mindfulness practice sessions appeared to be more helpful for Beth than Amy. One reason for this discrepancy could be due to the mutually reinforcing effect that the outside mindfulness practice had on the mindfulnessinformed interventions done during the therapy sessions, such as affective exposures, chain analyses, and the examination of Skillful Means. Beth's outside practice increased her willingness and openness to the interventions done in therapy, which in turn reinforced her practice by focusing on the same orientation towards experience-openness, curiosity, nonjudgmentalness - as her outside practice. Because Amy did not engage in the same level of outside practice as Beth, she was unable to take advantage of the mutually reinforcing nature of the out-of-session practice and in-session interventions; Amy's lack of outside practice likely reduced the effectiveness of the in-session interventions.

An additional factor likely affecting Amy's experience of the mindfulness practice had to do with the process of mindful inquiry that occurred during the practice sessions. During the sessions, Amy would frequently appear unsure of what to say when I inquired about her experience during any particular practice. At one point, during the session 12 pre-session practice, Amy said that she was unsure of what I was "looking for" and appeared frustrated when I told her that I wasn't looking for her to have a specific or “correct” response; this frustration continued into the therapy session, where we examined how this feeling was similar to what she experiences towards her father. It is possible that our mindfulness practice sessions re-created the interpersonal dynamic she experienced with her father, where I was the aloof authority figure 
and Amy was trying to please me, but was unsure of what I wanted her to do. Given this possible reenactment during the practice sessions, it is understandable that Amy's frustration prevented her from engaging fully in the practices, both in and out of session. Were I more attentive to the reenactment that took place, and had we addressed this reenactment, Amy may have had a more positive experience with mindfulness meditation.

Though I have covered both Beth's and Amy's reactions to the mindfulness practice sessions, and provided some possible reasons as to why their experiences differed, it should be noted that a great deal more could be written regarding the interplay between the mindfulness practice sessions and therapy sessions. I have limited the discussion in this article due to space constraints, but a fuller analysis of the impact of mindfulness meditation pre-session practices on the therapy sessions would be warranted in future studies utilizing this model.

Differences in the pattern of quantitative results compared to the qualitative results. Beth's OQ-45, Mindful Awareness Attachment Scale (MAAS), and the Nonattachment Scale (NAS) quantitative results are consistent with her qualitative results based on clinical observation and the therapy transcripts. Thus, both sources of data support the conclusion that Beth began therapy in a highly distressed state, with relatively little openness to mindfulness and nonattachment, while by the end of therapy, her distress had greatly decreased and she had substantially increased her engagement with mindfulness and nonattachment.

In contrast, Amy's OQ-45 results suggest more symptom reduction than the qualitative results indicate; and the initial and ending high scores on the MAAS and the NAS were discrepant with her behavioral difficulties in these areas throughout therapy. The results on all three of these measures seemed to reflect Amy's inclination towards telling me what she thought I wanted to hear (which, incidentally, is a re-enactment of her trying to figure out what to say to her father to make him happy and engage with her), and Amy's tendency towards minimizing her symptoms throughout the treatment.

Regarding the Working Alliance Inventory results, both Amy's decreased WAI scores and Beth's increased WAI scores were consistent with my observations of changes brought about throughout the therapy. Thus, Amy's decreasing WAI scores indicated her being more comfortable expressing her frustrations with me, while Beth's increasing WAI scores reflected a genuinely improving therapeutic relationship.

In sum, while the quantitative scores added substantially to an overall understanding of Beth and Amy's cases, it is important to note that for a full understanding of an individual case, quantitative and qualitative data is best interpreted as a pattern within the case, a point emphasized in the "mixed methods" measurement movement (e.g., Teddlie \& Tashakkori,2009).

\section{$\underline{\text { Integration of TLDP and the A/AMCS }}$}

As was planned and outlined in Section 3, Guiding Conception, the type of integration that took place between TLDP and the A/AMCS was in fact assimilative in nature; TLDP served as the home theory into which the A/AMCS was integrated. Specifically, in the context of the cases presented in this study, TLDP was used as a framework from which a basic formulation, 
treatment goals, and certain interventions derived. The A/AMCS was integrated into TLDP in two primary areas: case formulation and intervention. Conceptual details about this integration were presented in Section 3, Guiding Conception, and throughout both treatments I found it extremely helpful to have some conception of the clients' aversion/attachment patterns in the back of my mind. Whereas the "standard" sections of TLDP's Cyclical Maladaptive Pattern formulation provided me with the "what," "why," and "when” of the client's formulation, the clients' avoidance/attachment patterns provided me with the "how."

The interventions provided by the A/AMCS, such as the formal mindfulness practice sessions and the use of Skillful Means, were integrated into TLDP in that they explicitly served to meet the treatment goals of TLDP. For example, the A/AMCS concept of Skillful Means was used with both Beth and Amy to determine how best to interact with a specific situation, but the focus of the skillful action was almost entirely devoted to better getting TLDP-related attachment needs met and to engage in alternative TLDP-related interpersonal patterns. The use of A/AMCS's mindfulness meditation served a similar purpose: to better enable the clients' achievement of new TLDP-related interpersonal and intrapersonal experience and understanding.

While I believe that the integration of the A/AMCS into TLDP was successful in that the contributions of the A/AMCS to standard TLDP led to positive outcomes for both clients, the use of mindfulness meditation in treatment unfolded somewhat differently than I originally thought. Both Beth and Amy appeared interested during the mindfulness practice sessions, though they engaged in limited formal meditation practice outside of session. Because of this, I made an effort to utilize mindful inquiry during therapy in addition to the practice sessions. I chose to incorporate mindful inquiry into therapy sessions in order to underscore and reinforce what was being learned during practice sessions; in a way I hoped to "make up" for the lack of outside practice through my increased use of mindful inquiry.

Additionally, I found myself using the chain analysis technique from DBT (Linehan, 1993) as a way to examine situations with a mindful, observant quality. Through the completion of informal chain analyses, the clients and I were able to notice, together, the cascade of experience, thought, and emotion that made up an event. Over the course of both treatments, I came to think of our use of chain analyses as a sort of dyadic mindfulness practice, whereby I led the clients to notice their experience while embodying the "attitudinal foundations" (Woods, 2013) of mindfulness such as patience and non-judging.

\section{Limitations and Future Directions of This Study}

While this study represents a good first step towards the technical examination of the integration of mindfulness and Buddhist concepts into psychodynamic therapy, there are limitations that should be considered when applying this study to a broader treatment context. First, because this study was done as a single case design, a more controlled analysis of specific mechanisms of effectiveness in the treatments was not possible. Further controlled research is required to determine exactly how the addition of mindfulness and other Buddhist principles enhance the efficacy of current psychodynamic treatment. Additionally, more case studies are needed to expand the approach to a larger variety of clients. 
Finally, the aversion/attachment model I developed for this study drew from the Vipassana Buddhist tradition that is specific to the culture and time period of the modern United States. It would be useful for future research to examine practice and philosophy found outside of this Vipassana tradition, such as Zen or Tibetan Buddhism. What's more, the formal practices of compassion and loving-kindness were not included in the A/AMCS model I developed; both of these practices are central to the Vipassana tradition and are increasingly being used in psychotherapy (e.g., Germer \& Neff, 2013). I chose to omit formal self-compassion practices because I worried that depressed clients like Beth might have a negative reaction to them; there has been some literature indicating that self-compassion practice may have deleterious effects when used with such depressed individuals (Segal, Williams, \& Teasdale, 2012). Nevertheless, self-compassion could make a positive contribution to treatment outcome and should be examined as a component of treatment in future studies.

In sum and in broad terms, this study provides encouraging, systematic case study evidence of the value of integrating mindfulness and other Buddhist psychology concepts with short-term psychodynamic therapy. As such, Beth and Amy's case studies should encourage further research to expand the purview of such integration and the refinement of its effectiveness.

\section{REFERENCES}

Abbass, A., Kisely, S. \& Kroenke, K (2009). Short-Term Psychodynamic Psychotherapy for Somatic Disorders: Systematic review and meta-analysis of clinical trials. Psychotherapy and Psychosomatics, 78, 265-274.

Ainsworth, M. D. S. (1969) Object relations, dependency, and attachment: A theoretical review of the infant-mother relationship. Child Development, 40, 969-1025.

Ainsworth, M. D. S. (1986). Attachments beyond infancy. American Psychologist, 44, 709-716.

American Psychiatric Association. (2013). Diagnostic and Statistical Manual of Mental Disorders: $5^{\text {th }}$ Edition. Washington, DC: American Psychiatric Publishing.

Baraz, J. (2009, January 12). Learning to Open to Experience. [Audio Recording]. Spirit Rock Meditation Center. Retrieved from http://dharmaseed.org/talks.

Beck, A. T. \& Steer, R. A. (1993). Beck Anxiety Inventory Manual. San Antonio: Harcourt Brace and Company.

Beck, A. T., Steer, R. A., \& Brown, G. K. (1996). Manual for Beck Depression Inventory- II. San Antonio, TX: Psychological Corporation.

Benjamin, L. S. (1974). Structural analysis of social behavior. Psychological Review, 81, 392425.

Benjamin, L. S. (1993). Interpersonal diagnosis and treatment of personality disorders. New York, NY: Guilford Press.

Black, D. S. (2014). Mindfulness-Based Interventions: An antidote to suffering in the context of substance abuse, misuse, and addiction. Substance Use \& Misuse, 49, 487-491.

Bowlby, J. (1969). Attachment and loss: Vol. 1. Attachment. New York, NY: Basic Books.

Bowlby, J. (1973). Attachment and Loss: Vol. 2. Separation anxiety and anger. New York, NY: Basic Books. 
Pragmatic Case Studies in Psychotherapy, http://pcsp.libraries.rutgers.edu

Volume 12, Module 4, Article 1, pp. 238-308, 12-16-16 [copyright by author]

Bowlby, J. (1980). Attachment and Loss: Vol. 3. Loss, sadness, and depression. New York, NY: Basic Books.

Brown, K. W. \& Ryan, R. M. (2003) The benefits of being present: Mindfulness and its role in psychosocial wellbeing. Journal of Personality and Social Psychology, 84(4), 822-848.

Chiesa, A. \& Serretti, A. (2009). Mindfulness-based stress reduction for healthy people: A review and meta-analysis. Journal of Alternative and Complimentary Medicine, 15, 593.

Chiesa, A. \& Serretti, A. (2011). Mindfulness based cognitive therapy for psychiatric disorders: A systematic review and meta-analysis. Psychiatry Research, 187, 441.

Coleman, M. (2013, April 6). Freedom to Choose. [Audio Recording]. Spirit Rock Meditation Center. Retrieved from http://dharmaseed.org/talks.

Crane, C., Crane, R. S., Eames, C., Fennell, M. J. V., Silverton, S., Williams, J. M. G. \& Barnhofer, T. (2014). The effects of amount of home practice in Mindfulness Based Cognitive Therapy on hazard of relapse to depression in the Staying Well After Depression Trial. Behaviour Research and Therapy, 63, 17-24.

Cullen, C. (2011, August 1). Turning Towards Dukkha - The Four Noble Truths [Audio Recording]. Gaia House. Retrieved from http://dharmaseed.org/talks.

DeMartino, R. J. (1991) Karen Horney, Daisetz T. Suzuki, and Zen Buddhism. The American Journal of Psychoanalysis, 51(3).

Driessen, E., Cuiipers,P., deMaat, S. C., Abbass, A. A., dejonghe, F., Dekker, J. J., (2010). The efficacy of short-term psychodynamic psychotherapy for depression: a meta-analysis. Clinical Psychology Review, 30, 25-36.

de Vibe, M., Bjørndal, A., Tipton, E.,... Kowalski, K. (2012). Mindfulness based stress reduction (MBSR) for improving health, quality of life, and social functioning in adults. The Campbell Collaboration, 3.

Epstein, M. (1995). Thoughts without a thinker: Psychotherapy from a Buddhist Perspective. New York, NY: Basic Books.

Epstein, M. (2008). Psychotherapy without the self: A Buddhist perspective on wholeness. New Haven, CT: Yale University Press.

Feldman, C., \& Kuyken, W. (2011). Compassion in the landscape of suffering. Contemporary Buddhism, 12, 143-155.

Fields, R. (1981). How the swans came to the lake: A narrative history of Buddhism in America. Boulder, CO: Shambhala.

Fishman, D. B. (2005). From single case to database: A new method for enhancing psychotherapy practice. Pragmatic Case Studies in Psychotherapy, 1(1), Article 2, pp. 150. Available: pcsp.libraries.rutgers.edu. doi: http://dx.doi.org/10.14713/pcsp.v1i1.855

Fosha, D. (2000). The transforming power of affect: A model for accelerated change. New York, NY: Basic Books.

Fromm, E., Suzuki, D. T., \& DeMartino, R. J. (1960). Zen Buddhism and psychoanalysis. Oxford, England: Harper.

Frondsal, G. (1998). Insight meditation in the United States: Life, liberty, and the pursuit of happiness. In C.S. Prebish, \& K. Tanaka (Eds.), The faces of Buddhism in America, pp. 163-182. Berkeley, CA: The University of California Press.

Fulton, P. R., \& Siegel, R. D. (2005). Buddhist and western psychology: Seeking common ground. In C. K. Germer, R. D. Segal, \& P. R. Fulton (Eds.), Mindfulness and psychotherapy. New York: Guilford Press. 
Pragmatic Case Studies in Psychotherapy, http://pcsp.libraries.rutgers.edu

Volume 12, Module 4, Article 1, pp. 238-308, 12-16-16 [copyright by author]

Germer, C. K. \& Neff, K. D. (2013). Self-Compassion in clinical practice. Journal of Clinical Psychology, 69, 856-867.

Goldstein, J. (2010, May 18). Doubt and aversion: Understanding how they influence our practice and our lives. [Audio Recording]. Insight Meditation Society: Forest Refuge. Retrieved from http://dharmaseed.org/talks.

Greenberg, L. S. (2002). Emotion-focused therapy: Coaching clients to work through their feelings. Washington, DC: American Psychological Association.

Greenberg, L. S., \& Pascual-Leone, J. (2006). Emotion in psychotherapy: A practice friendly research review. Journal of Clinical Psychology: In Session,62, 611-630.

Harrist, R. S., Quintana, S. M., Strupp, H. H., \& Henry, W. P. (1994). Internalization of interpersonal process in Time-Limited Dynamic Psychotherapy. Psychotherapy, 31(1).

Hayes, S. C., Strosahl, K. D., \& Wilson, K. G. (2011). Acceptance and commitment therapy: The process and practice of mindful change, $2^{\text {nd }}$ Ed. New York, NY: Guilford Press.

Hayes, S. C., Wilson, K. G., Gifford, E. V., Follette, V. M., \& Strosahl, K. D. (1996). Experiential avoidance and behavioral disorders: A functional dimensional approach to diagnosis and treatment. Journal of Consulting and Clinical Psychology, 64, 1152-1168.

Hick, S. F. \& Bien, T. (2008). Mindfulness and the therapeutic relationship. New York, NY: Guilford Press.

Jacobson, N. S., \& Truax, P. (1991). Clinical significance: A statistical approach to defining meaningful change in psychotherapy research. Journal of Consulting and Clinical Psychology, 59, 12-19.

Kabat-Zinn, J. (1990). Full catastrophe living. McHenry, IL: Delta Publishing.

Kabat-Zinn, J. (2003). Mindfulness-based interventions in context: Past, present, and future.

Clinical Psychology: Science and Practice, 10, 144-156.

Kumar, S. M. (2002). An introduction to Buddhism for the cognitive-behavioral therapist.

Cognitive and Behavioral Practice, 9, 40-43.

Lambert, M. J., Burlingame, G. M., Umphress, V., Hansen, N. B., Vermeersch, D. A., Clouse, G. C., \& Yanchar, S. C. (1996). The reliability and validity of the outcome questionnaire. Clinical Psychology and Psychotherapy, 4, 249-258.

Lambert, M.J., Morton, J. J., Hatfield, D., Harmon, C., Hamilton, S., Reid, R. C., Shimokawa, K., Christopherson, C., \& Burlingame, G. B. (2004). Administration and scoring manual for the OQ-45.2 (Outcome Questionnaire). Orem, UT: American Professional Credentialing Services.

Lampropoulous, G. K. (2001). Bridging technical eclecticism and theoretical integration: Assimilative integration. Journal of Psychotherapy Integration, 11, 5-19.

Levenson, H. (1995). Time-limited dynamic psychotherapy: A guide to clinical practice. New York: Basic Books.

Levenson, H. (2010). Brief dynamic therapy, Washington DC: American Psychological Association.

Linehan, M. (1993). Cognitive-behavioral treatment of borderline personality disorder. New York, NY: Guilford Press.

McCullough, L., Kuhn, N., Andrews, S., Kaplan, A., Wolf, J., \& Hurley, C. L. (2003). Treating affect phobia: A manual for short-term dynamic psychotherapy. New York, NY: Guilford Press. 
Pragmatic Case Studies in Psychotherapy, http://pcsp.libraries.rutgers.edu

Volume 12, Module 4, Article 1, pp. 238-308, 12-16-16 [copyright by author]

McDonald, M. (2000, June 10). Courage, right effort, and freedom. [Audio Recording]. Insight Meditation Society: Retreat Center. Retrieved from http://dharmaseed.org/talks.

McMahan, D. L. (2008). The making of Buddhist modernism. New York, NY: Oxford University Press.

Messer, S. B. (1992). A critical examination of belief structures in integrative and eclectic psychotherapy. In J. C. Norcross \& M. R. Goldfried (Eds.), Handbook of psychotherapy integration, pp. 130-165. New York: Basic Books.

Messer, S. B., \& Warren, C. S. (1995). Models of brief psychodynamic therapy: A comparative approach. New York: Guilford Press.

Olendzki, A. (2003). Buddhist psychology. In S.R. Segall (Ed.), Encountering Buddhism: Western psychology and Buddhist teachings, pp. 9-30. Albany: State University of New York Press.

Olendzki, A. (2005). Glossary of terms in Buddhist psychology. In C. K. Germer, R. D. Segal, \& P. R. Fulton (Eds.), Mindfulness and psychotherapy. New York: Guilford Press.

Olenzki, A. (2010). Unlimiting mind: The radically experiential psychology of Buddhism. Boston, MA: Wisdom Publications.

Panos, P. T., Jackson, J. W., Hasan, O., \& Panos, A. (2014). Meta-Analysis and systematic review assessing the efficacy of Dialectical Behavior Therapy (DBT). Research on Social Work Practice, 24, 213-223.

Piet, J. \& Hougaard, E. (2011). The effect of mindfulness-based cognitive therapy for prevention of relapse in recurrent major depressive disorder: A systematic review and meta-analysis. Clinical Psychology Review, 31, 1032-1040.

Pollak, S. M., Pedulla, T., \& Siegel, R. D. (2014). Sitting together: Essential skills for Mindfulness-Based Psychotherapy. New York, NY: Guilford Press.

Pye, M. (2003). Skillful means: A concept in Mahayana Buddhism, $2^{\text {nd }}$ Ed. New York, NY: Routledge.

Rothberg, D. (2014, July 9). Practicing with Challenges I - Cultivating responsiveness [Audio Recording]. Spirit Rock Meditation Center. Retrieved from http://dharmaseed.org/talks.

Safran, J. D. (2003). Introduction: Psychoanalysis and Buddhism as cultural institutions. In J. D. Safran (Ed.), Psychoanalysis and Buddhism: An unfolding dialogue, pp. 1-34. Boston: Wisdom Publications.

Safran, J. D. \& Muran, J. C. (2000). Negotiating the therapeutic alliance: A relational treatment guide. New York: Guilford.

Sahdra, B. K., Shaver, P. R., \& Brown, K. W. (2010). A scale to measure nonattachment: A Buddhist complement to western research on attachment and adaptive functioning. Journal of Personality Functioning, 92(2), 116-127.

Samlin, J.M. (2015). A qualitative study examining the integration of short-term dynamic therapy and the aversion/attachment model of client suffering. Unpublished doctoral dissertation, Rutgers University, Piscataway, NJ. Available at: https://rucore.libraries.rutgers.edu/search/results/?key=ETDRU\&rtype\%5B\%5D=\&query=samlin

Santorelli, S. (1999). Heal thy self: Lessons on mindfulness in medicine. New York, NY: Three Rivers Press. 
Segal, Z. V., Williams, J. M. G., \& Teasdale, J. D. (2012). Mindfulness-Based Cognitive Therapy for depression, $2^{\text {nd }}$ Ed. New York, NY: Guilford Press.

Shedler,J. (2010). The efficacy of psychodynamic psychotherapy. American Psychologist 65, 98-109.

Society of Clinical Psychology. (2014). Website of research supported psychological treatments. http://www.div12.org/PsychologicalTreatments/treatments.html

Sullivan, H. S. (1953). The interpersonal theory of psychiatry. New York, NY: Norton.

Swain, J., Hancock, K., Hainsworth, C., Bowman, J. (2013). Acceptance and Commitment Therapy in the treatment of anxiety: A systematic review. Clinical Psychology Review, 33, 965-978.

Teddlie, C., \& Tashakkori, A. (2009). Foundations of mixed methods research: Integrating quantitative and qualitative approaches in the social and behavioral sciences. Thousand Oaks, CA: Sage Publications.

Tracey, T. J., \& Kokotovic, A. M. (1989). Factor structure of the Working Alliance Inventory. Psychological Assessment, 1, 207-210.

Travis, L. A., Bliwise, N. G., Binder, J. L., \& Horne-Moyer, H. L. (2001). Changes in clients' attachment styles over the course of Time-Limited Dynamic Psychotherapy. Psychotherapy: Theory, Research, Practice, Training, 38, 149-159.

Wetherell, J. L., Afari, N., Rutledge, T., Lehman, D. H., Hampton Atkinson, J., [...] \& Soloman, B. C. (2011). A randomized, controlled trial of acceptance and commitment therapy and cognitive-behavioral therapy for chronic pain. Pain, 152, 2098-2107.

Wilks, J. (2014, February 18). Non-judgment and wise discernment. [Audio Recording]. Gaia House. Retrieved from http://dharmaseed.org/talks.

Woods, S. L. (2013). A framework for mindful inquiry. Retrieved from http://www.slwoods.com/articles.php. 


\section{Table 1. Inclusion and Exclusion Criteria}

\section{Inclusion Criteria \\ - $\quad$ Subjects are between 18 and 55 years of} age.

- Subjects will be fluent in English.

- Subjects must be willing to consider how their relationships have contributed to their current difficulties

- Subjects must be experiencing sufficient emotional distress to be motivated to engage in treatment.

- The subjects' personal history should suggest a capacity to relate to the clinician and to tolerate separation between sessions and at the end of treatment without experiencing intense discomfort.

- Subjects must have the capacity to distance themselves emotionally from their feelings so that these may be examined.

\section{Exclusion Criteria}

- Inability to engage in meaningful verbal exchange with the clinician due to impairment such as, but not limited to: psychosis, dementia, developmental disability, severe problems with attention and concentration, or diminished intellectual capacities.

- The subject engages in behaviors that threaten to significantly interfere with the treatment process and/or pose the risk of harm to self or other (e.g., impulse-control problems, drug and/or alcohol abuse, current suicidality).

- The subject is currently taking psychiatric medication that would directly interfere with treatment. 
Table 2. Beth's Scores on the Outcome Questionnaire-45

\begin{tabular}{|l|l|l|l|l|}
\hline Session Number & Total Score* & $\begin{array}{l}\text { Symptoms } \\
\text { Distress Score* }\end{array}$ & $\begin{array}{l}\text { Interpersonal } \\
\text { Relations Score* }\end{array}$ & $\begin{array}{l}\text { Social Role } \\
\text { Score* }\end{array}$ \\
\hline 1 & $107^{\wedge}$ & $67^{\wedge}$ & $20^{\wedge}$ & $20^{\wedge}$ \\
\hline 2 & $93^{\wedge}$ & $63^{\wedge}$ & $17^{\wedge}$ & $13^{\wedge}$ \\
\hline 3 & $97^{\wedge}$ & $66^{\wedge}$ & $18^{\wedge}$ & $13^{\wedge}$ \\
\hline 4 & $95^{\wedge}$ & $66^{\wedge}$ & $17^{\wedge}$ & $12^{\wedge}$ \\
\hline 5 & $90^{\wedge}$ & $60^{\wedge}$ & $18^{\wedge}$ & $16^{\wedge}$ \\
\hline 6 & $80^{\wedge}$ & $52^{\wedge}$ & $16^{\wedge}$ & $12^{\wedge}$ \\
\hline 7 & 44 & 31 & 9 & 4 \\
\hline 8 & 51 & 32 & 14 & 5 \\
\hline 9 & 60 & $36^{\wedge}$ & $17^{\wedge}$ & 7 \\
\hline 10 & $70^{\wedge}$ & $43^{\wedge}$ & $18^{\wedge}$ & 9 \\
\hline 11 & $66^{\wedge}$ & $45^{\wedge}$ & 14 & 7 \\
\hline 12 & 51 & 31 & 13 & 7 \\
\hline 13 & 59 & 35 & $17^{\wedge}$ & 7 \\
\hline 14 & 63 & 34 & $17^{\wedge}$ & $12^{\wedge}$ \\
\hline 15 & 59 & $41^{\wedge}$ & $18^{\wedge}$ & 10 \\
\hline 16 & $83^{\wedge}$ & $47^{\wedge}$ & $21^{\wedge}$ & $15^{\wedge}$ \\
\hline 17 & $74^{\wedge}$ & $42^{\wedge}$ & $20^{\wedge}$ & $12^{\wedge}$ \\
\hline 18 & 60 & 32 & $20^{\wedge}$ & 8 \\
\hline 19 & 55 & 32 & $15^{\wedge}$ & 8 \\
\hline 20 & 45 & 23 & $15^{\wedge}$ & 7 \\
\hline 21 & 35 & 17 & 12 & 6 \\
\hline 22 & 33 & 15 & 11 & 7 \\
\hline 23 & $27^{\mathrm{a}}$ & $12^{\mathrm{a}}$ & 9 & $6^{\mathrm{a}}$ \\
\hline
\end{tabular}

* Clinical cut-off scores for this measure are the following: Total Score of 63 or above; Symptoms Distress Score of 36 or above; Interpersonal Relations Score of 15 or above; and Social Role Score of 12 or above (Lambert et al., 2004).

$\wedge$ Scores fall above the clinical cut-off, indicating impairment in functioning.

${ }^{a}$ Decrease between first and last session scores are statistically significant as measured by Jacobson and Truax’s (1991) Reliable Change Index. 


\section{Table 3. Beth's Scores on the Beck Depression Inventory, $2^{\text {nd }}$ Edition}

\begin{tabular}{|l|l|l|}
\hline Session & Score & Severity Classification* \\
\hline 1 & 31 & Severe depression \\
\hline 2 & 33 & Severe depression \\
\hline 3 & 33 & Severe depression \\
\hline 4 & 33 & Severe depression \\
\hline 5 & 30 & Severe depression \\
\hline 6 & 19 & Mild depression \\
\hline 7 & 8 & Minimal depression \\
\hline 8 & 12 & Minimal depression \\
\hline 9 & 15 & Mild depression \\
\hline 10 & 20 & Moderate depression \\
\hline 11 & 20 & Moderate depression \\
\hline 12 & 17 & Mild depression \\
\hline 13 & 9 & Minimal depression \\
\hline 14 & 19 & Mild depression \\
\hline 15 & 10 & Minimal depression \\
\hline 16 & 14 & Mild depression \\
\hline 17 & 28 & Moderate depression \\
\hline 18 & 19 & Mild depression \\
\hline 19 & 7 & Minimal depression \\
\hline 20 & 6 & Minimal depression \\
\hline 21 & 3 & Minimal depression \\
\hline 22 & 0 & Minimal depression \\
\hline 23 & 0 & Minimal depression \\
\hline
\end{tabular}

* Score severity classification as found in the Manual for the Beck Depression Inventory - II (Beck, Steer, \& Brown, 1996). 


\section{Table 4. Beth's Scores on the Beck Anxiety Inventory}

\begin{tabular}{|c|c|c|}
\hline Session & Score & Severity Classification* \\
\hline 1 & 30 & Severe anxiety \\
\hline 2 & 11 & Mild anxiety \\
\hline 3 & 31 & Severe anxiety \\
\hline 4 & 14 & Mild anxiety \\
\hline 5 & 30 & Severe anxiety \\
\hline 6 & 9 & Mild anxiety \\
\hline 7 & 5 & Minimal anxiety \\
\hline 8 & 2 & Minimal anxiety \\
\hline 9 & 3 & Minimal anxiety \\
\hline 10 & 12 & Mild anxiety \\
\hline 11 & 11 & Mild anxiety \\
\hline 12 & 8 & Mild anxiety \\
\hline 13 & 4 & Minimal anxiety \\
\hline 14 & 6 & Minimal anxiety \\
\hline 15 & 2 & Minimal anxiety \\
\hline 16 & 11 & Mild anxiety \\
\hline 17 & 5 & Minimal anxiety \\
\hline 18 & 2 & Minimal anxiety \\
\hline 19 & 3 & Minimal anxiety \\
\hline 20 & 2 & Minimal anxiety \\
\hline 21 & 3 & Minimal anxiety \\
\hline 22 & 2 & Minimal anxiety \\
\hline 23 & 0 & Minimal anxiety \\
\hline
\end{tabular}

* Score severity classification as found in the Beck Anxiety Inventory Manual (Beck \& Steer, 1993). 
Table 5. Beth's Scores on the Working Alliance Inventory

\begin{tabular}{|l|l|l|l|l|}
\hline Session & Task & Bond & Goal & Total \\
\hline 3 & 18 & 20 & 22 & 60 \\
\hline 5 & 17 & 20 & 21 & 58 \\
\hline 7 & 22 & 26 & 26 & 74 \\
\hline 9 & 21 & 24 & 18 & 63 \\
\hline 11 & 18 & 25 & 23 & 66 \\
\hline 13 & 18 & 25 & 18 & 61 \\
\hline 15 & 21 & 25 & 21 & 67 \\
\hline 17 & 20 & 25 & 22 & 67 \\
\hline 19 & 24 & 27 & 22 & 73 \\
\hline 21 & 23 & 27 & 23 & 73 \\
\hline 23 & $24^{\mathrm{a}}$ & $27^{\mathrm{a}}$ & $26^{\mathrm{a}}$ & $77^{\mathrm{b}}$ \\
\hline
\end{tabular}

${ }^{a}$ Increase between first and last session scores are statistically significant as measured by Jacobson and Truax’s (1991) Reliable Change Index.

${ }^{a}$ Psychometric data were not available to compute a Reliable Change Index between the first and last sessions.

Table 6. Beth's Scores on the Mindful Awareness Attachment Scale

\begin{tabular}{|l|l|}
\hline Session & Score \\
\hline 1 & 2.4 \\
\hline 23 & $4^{\mathrm{a}}$ \\
\hline
\end{tabular}

${ }^{a}$ Increase between first and last session scores are statistically significant as measured by Jacobson and Truax’s (1991) Reliable Change Index.

Table 7. Beth's Scores on the Nonattachment Scale

\begin{tabular}{|l|l|}
\hline Session & Score \\
\hline 1 & 2.4 \\
\hline 23 & $4.7^{\mathrm{a}}$ \\
\hline
\end{tabular}

${ }^{\mathrm{a}}$ Psychometric data were not available to compute a Reliable Change Index between the first and last sessions. 
Pragmatic Case Studies in Psychotherapy, http://pcsp.libraries.rutgers.edu

Volume 12, Module 4, Article 1, pp. 238-308, 12-16-16 [copyright by author]

Table 8. Summary of Beth's Mindfulness Practice Sessions

\begin{tabular}{|c|c|c|c|c|}
\hline Session & Practice & $\begin{array}{l}\text { Number of } \\
\text { practices } \\
\text { done since } \\
\text { last session }\end{array}$ & Content & Homework \\
\hline 6 & $\begin{array}{l}\text { Introductory } \\
\text { three-minute } \\
\text { breathing space; } \\
\text { overview of } \\
\text { mindfulness; } \\
\text { mindfulness of } \\
\text { breath. }\end{array}$ & & $\begin{array}{l}\text { Session began with three-minute } \\
\text { breathing space as utilized in MBCT } \\
\text { (Segal, Williams, \& Teasdale, } \\
\text { 2012). Therapist then explained } \\
\text { mindfulness, and Beth appeared to } \\
\text { understand and did not ask any } \\
\text { questions. After the mindfulness of } \\
\text { breathing exercise, Beth said that } \\
\text { she "dozed off a couple times" and } \\
\text { noticed herself trying to "figure out } \\
\text { how the stories in my head ran } \\
\text { together." }\end{array}$ & $\begin{array}{l}\text { Daily 10-minute } \\
\text { mindfulness of the } \\
\text { breath practice. } \\
\text { Gave Beth a CD } \\
\text { of guided } \\
\text { meditations to use } \\
\text { during homework. }\end{array}$ \\
\hline 7 & $\begin{array}{l}\text { Introductory } \\
\text { three-minute } \\
\text { breathing space; } \\
\text { mindfulness of } \\
\text { breath. }\end{array}$ & 2 & $\begin{array}{l}\text { After the three-minute breathing } \\
\text { space, Beth described how she had } \\
\text { only practiced twice the past week. } \\
\text { Therapist encouraged Beth to notice } \\
\text { her guilt, disappointment without } \\
\text { judgment. After mindfulness of } \\
\text { breath, Beth and therapist examined } \\
\text { Beth's experience of "breathing } \\
\text { weird” during the practice. } \\
\text { Examined how Beth could practice } \\
\text { more over the next week. }\end{array}$ & $\begin{array}{l}\text { Continue daily } \\
\text { mindfulness of } \\
\text { breath practice. }\end{array}$ \\
\hline 8 & $\begin{array}{l}\text { Introductory } \\
\text { three-minute } \\
\text { breathing space; } \\
\text { sitting body scan. }\end{array}$ & 3 & $\begin{array}{l}\text { Beth discussed meditating when } \\
\text { having difficulty sleeping. Beth said } \\
\text { she "zoned out" for a portion of the } \\
\text { body scan. Beth and therapist } \\
\text { examined her experience of zoning } \\
\text { out. }\end{array}$ & $\begin{array}{l}\text { At least one } \\
\text { sitting meditation } \\
\text { and one body } \\
\text { scan. Given } \\
\text { chapter } 2 \text { of Full } \\
\text { Catastrophe } \\
\text { Living (Kabat- } \\
\text { Zinn, 1990) to } \\
\text { read. }\end{array}$ \\
\hline
\end{tabular}


Table 8. continued

\begin{tabular}{|c|c|c|c|c|}
\hline Session & Practice & $\begin{array}{l}\text { Number of } \\
\text { practices } \\
\text { done since } \\
\text { last session }\end{array}$ & Content & Homework \\
\hline 9 & $\begin{array}{l}\text { Introductory } \\
\text { three-minute } \\
\text { breathing space; } \\
\text { discussion of } \\
\text { meditation } \\
\text { difficulties }\end{array}$ & 4 & $\begin{array}{l}\text { Beth said she had difficulty “staying } \\
\text { with” three-minute breathing space. } \\
\text { She then discussed her difficulty } \\
\text { practicing when she felt like she wasn’t } \\
\text { "doing it” right. Therapist normalized } \\
\text { her experience and discussed the } \\
\text { "evaluative mind.” }\end{array}$ & $\begin{array}{l}\text { Continue practicing } \\
\text { at least one sitting } \\
\text { meditation and one } \\
\text { body scan. }\end{array}$ \\
\hline 10 & $\begin{array}{l}\text { Introductory } \\
\text { three-minute } \\
\text { breathing space; } \\
\text { taught three- } \\
\text { minute breathing } \\
\text { space; informal } \\
\text { practice. }\end{array}$ & 0 & $\begin{array}{l}\text { Beth discussed how stressors have made } \\
\text { it difficult to practice; noticed the } \\
\text { stressors coming up during introductory } \\
\text { practice. Beth and therapist discussed } \\
\text { Beth's worry that the therapist would be } \\
\text { disappointed she didn't practice. Beth } \\
\text { identified washing dishes as a potential } \\
\text { informal mindfulness activity. }\end{array}$ & $\begin{array}{l}\text { Practice three- } \\
\text { minute breathing } \\
\text { space at least once } \\
\text { a day; informal } \\
\text { practice. }\end{array}$ \\
\hline 11 & $\begin{array}{l}\text { Introductory } \\
\text { three-minute } \\
\text { breathing space; } \\
\text { discussion of } \\
\text { practice. }\end{array}$ & 5 & $\begin{array}{l}\text { Beth and therapist processed Beth's } \\
\text { "wandering mind" during intro practice. } \\
\text { Beth reported practicing the breathing } \\
\text { space driving home from work. } \\
\text { Discussion around Beth's experience of } \\
\text { "stillness" when practicing. }\end{array}$ & $\begin{array}{l}\text { Continue practicing } \\
\text { three-minute } \\
\text { breathing space and } \\
\text { informal practice. }\end{array}$ \\
\hline 12 & $\begin{array}{l}\text { Introductory } \\
\text { three-minute } \\
\text { breathing space; } \\
\text { sitting mindful } \\
\text { yoga. }\end{array}$ & $\begin{array}{l}5 \text { (informal } \\
\text { practice } \\
\text { while } \\
\text { driving) }\end{array}$ & $\begin{array}{l}\text { Beth said she has not done formal } \\
\text { practice because she has forgotten. } \\
\text { After mindful yoga practice, Beth said } \\
\text { she felt her body become "heavy" and } \\
\text { noticed that she was worried she was } \\
\text { not practicing correctly. }\end{array}$ & $\begin{array}{l}\text { Practice mindful } \\
\text { yoga at least three } \\
\text { times. Informal } \\
\text { practice. }\end{array}$ \\
\hline 13 & $\begin{array}{l}\text { Introductory } \\
\text { three-minute } \\
\text { breathing space; } \\
\text { processing end of } \\
\text { practice sessions. }\end{array}$ & $\begin{array}{l}5 \text { (only } \\
\text { informal } \\
\text { practice } \\
\text { while } \\
\text { driving) }\end{array}$ & $\begin{array}{l}\text { Beth said that she found the informal } \\
\text { practice the most helpful because, "I } \\
\text { can just let things be there." She said } \\
\text { that she could "never find the time" to } \\
\text { do formal practice. Beth and therapist } \\
\text { examined how she could use the three- } \\
\text { minute breathing space in her daily life. }\end{array}$ & \\
\hline
\end{tabular}


Table 9. Amy’s Scores on the Outcome Questionnaire-45

\begin{tabular}{|l|l|l|l|l|}
\hline Session & Total Score* & $\begin{array}{l}\text { Symptom Distress } \\
\text { Score* }\end{array}$ & $\begin{array}{l}\text { Interpersonal } \\
\text { Relations score* }\end{array}$ & $\begin{array}{l}\text { Social Role } \\
\text { Score* }\end{array}$ \\
\hline 1 & 51 & 28 & 12 & 11 \\
\hline 2 & 49 & 28 & 11 & 10 \\
\hline 3 & 47 & 27 & 11 & 9 \\
\hline 4 & 39 & 20 & 8 & 11 \\
\hline 5 & 37 & 17 & 11 & 9 \\
\hline 6 & 26 & 10 & 7 & 9 \\
\hline 7 & 37 & 18 & 11 & 8 \\
\hline 8 & 39 & 22 & 10 & 7 \\
\hline 9 & 21 & 9 & 8 & 4 \\
\hline 10 & 28 & 12 & 10 & 6 \\
\hline 11 & 19 & 7 & 9 & 3 \\
\hline 12 & 24 & 11 & 8 & 5 \\
\hline 13 & 26 & 12 & 8 & 6 \\
\hline 14 & 33 & 15 & 12 & 6 \\
\hline 15 & 34 & 19 & 10 & 5 \\
\hline 16 & 25 & 12 & 6 & 7 \\
\hline 17 & 27 & 17 & 5 & 5 \\
\hline 18 & 28 & 16 & 7 & 5 \\
\hline 19 & 32 & 16 & 10 & $16^{\wedge}$ \\
\hline 20 & $24^{\mathrm{a}}$ & $15^{\mathrm{a}}$ & $4^{\mathrm{a}}$ & 5 \\
\hline
\end{tabular}

* Clinical cut-off scores for this measure are the following: Total Score of 63 or above; Symptoms Distress Score of 36 or above; Interpersonal Relations Score of 15 or above; and Social Role Score of 12 or above (Lambertet al., 2004).

$\wedge$ Scores fall above the clinical cut-off, indicating impairment in functioning.

${ }^{a}$ Decrease between first and last session scores are statistically significant as measured by Jacobson and Truax’s (1991) Reliable Change Index. 


\section{Table 10. Amy's Score on the Beck Anxiety Inventory}

\begin{tabular}{|l|l|l|}
\hline Session & Score & Severity Classification* \\
\hline 1 & 5 & Minimal anxiety \\
\hline 2 & 8 & Mild Anxiety \\
\hline 3 & 3 & Minimal anxiety \\
\hline 4 & 2 & Minimal anxiety \\
\hline 5 & 4 & Minimal anxiety \\
\hline 6 & 2 & Minimal anxiety \\
\hline 7 & 7 & Minimal anxiety \\
\hline 8 & 2 & Minimal anxiety \\
\hline 9 & 1 & Minimal anxiety \\
\hline 10 & 1 & Minimal anxiety \\
\hline 11 & 1 & Minimal anxiety \\
\hline 12 & 0 & Minimal anxiety \\
\hline 13 & 2 & Minimal anxiety \\
\hline 14 & 1 & Minimal anxiety \\
\hline 15 & 0 & Minimal anxiety \\
\hline 16 & 2 & Minimal anxiety \\
\hline 17 & 1 & Minimal anxiety \\
\hline 18 & 2 & Minimal anxiety \\
\hline 19 & 1 & Minimal anxiety \\
\hline 20 & 1 & Minimal anxiety \\
\hline
\end{tabular}

* Score severity classification as found in the Beck Anxiety Inventory Manual (Beck \& Steer, 1993). 
Pragmatic Case Studies in Psychotherapy, http://pcsp.libraries.rutgers.edu

Volume 12, Module 4, Article 1, pp. 238-308, 12-16-16 [copyright by author]

Table 11. Amy's Scores on the Working Alliance Inventory

\begin{tabular}{|l|l|l|l|l|}
\hline Session & Task & Bond & Goal & Total \\
\hline 4 & 27 & 27 & 27 & 81 \\
\hline 6 & 24 & 24 & 23 & 71 \\
\hline 8 & 21 & 21 & 21 & 63 \\
\hline 10 & 21 & 24 & 24 & 69 \\
\hline 12 & 24 & 24 & 24 & 72 \\
\hline 14 & 24 & 21 & 24 & 69 \\
\hline 16 & 20 & 21 & 22 & 63 \\
\hline 18 & 23 & 22 & 22 & 67 \\
\hline 20 & 23 & $23^{\mathrm{a}}$ & 24 & 70 \\
\hline
\end{tabular}

${ }^{a}$ Increase between first and last session scores are statistically significant as measured by Jacobson and Truax’s (1991) Reliable Change Index.

Table 12. Amy's Scores on the Mindful Awareness Attachment Scale

\begin{tabular}{|l|l|}
\hline Session & Score \\
\hline 1 & 4.6 \\
\hline 20 & 4.6 \\
\hline
\end{tabular}

Table 13. Amy's Scores on the Nonattachment Scale

\begin{tabular}{|l|l|}
\hline Session & Score \\
\hline 1 & 4.8 \\
\hline 20 & 4.5 \\
\hline
\end{tabular}


Pragmatic Case Studies in Psychotherapy, http://pcsp.libraries.rutgers.edu

Volume 12, Module 4, Article 1, pp. 238-308, 12-16-16 [copyright by author]

Table 14. Summary of Amy’s Mindfulness Practice Sessions

\begin{tabular}{|c|c|c|c|c|}
\hline Session & Practices & $\begin{array}{l}\text { Number of } \\
\text { practices } \\
\text { done since } \\
\text { last session }\end{array}$ & Content & Homework \\
\hline 6 & $\begin{array}{l}\text { Introductory three- } \\
\text { minute breathing } \\
\text { space; overview of } \\
\text { mindfulness; } \\
\text { mindfulness of } \\
\text { breath. }\end{array}$ & & $\begin{array}{l}\text { Amy said that her mind was } \\
\text { "all over the place" and that it } \\
\text { was "hard to focus and pay } \\
\text { attention to the instructions." } \\
\text { She and the therapist } \\
\text { discussed her fear that she } \\
\text { was meditating incorrectly. }\end{array}$ & $\begin{array}{l}\text { Daily 10-minute } \\
\text { mindfulness of the } \\
\text { breath practice. Gave } \\
\text { Beth a CD of guided } \\
\text { meditations to use } \\
\text { during homework. } \\
\text { Given chapter } 2 \text { of } \\
\text { Full Catastrophe } \\
\text { Living (Kabat-Zinn, } \\
\text { 1990) to read. }\end{array}$ \\
\hline 7 & $\begin{array}{l}\text { Introductory three- } \\
\text { minute breathing } \\
\text { space; mindfulness } \\
\text { of breath. }\end{array}$ & 3 & $\begin{array}{l}\text { Amy said that she had } \\
\text { difficulty finding a quiet } \\
\text { space in her house to practice. } \\
\text { She also said she was worried } \\
\text { she was "doing it wrong" and } \\
\text { would not get any benefit } \\
\text { from the practice. After the } \\
\text { breath meditation, Amy said } \\
\text { that "it felt like a good time to } \\
\text { plan stuff" and the therapist } \\
\text { discussed her tendency to "go } \\
\text { with the thought stream.” }\end{array}$ & $\begin{array}{l}\text { Continue daily } \\
\text { practice of breath } \\
\text { meditation. }\end{array}$ \\
\hline 8 & $\begin{array}{l}\text { Introductory three- } \\
\text { minute breathing } \\
\text { space; sitting body } \\
\text { scan. }\end{array}$ & 4 & $\begin{array}{l}\text { Amy reported doing breath } \\
\text { meditations before bed, } \\
\text { during which she "kept trying } \\
\text { to get rid of sleepiness." } \\
\text { Amy noticed bodily } \\
\text { restlessness during the body } \\
\text { scan, after which she and the } \\
\text { therapist discussed the } \\
\text { aversive nature of } \\
\text { restlessness. }\end{array}$ & $\begin{array}{l}\text { At least one sitting } \\
\text { meditation and body } \\
\text { scan. }\end{array}$ \\
\hline
\end{tabular}


Integrating Short-Term Dynamic Psychotherapy and a Buddhism-Inspired

Aversion/Attachment Model of Client Suffering: The Cases of "Beth" and "Amy"

J. M. Samlin

Pragmatic Case Studies in Psychotherapy, http://pcsp.libraries.rutgers.edu

Volume 12, Module 4, Article 1, pp. 238-308, 12-16-16 [copyright by author]

Table 14. continued

\begin{tabular}{|c|c|c|c|c|}
\hline Session & Practices & $\begin{array}{l}\text { Number of } \\
\text { practices } \\
\text { done since } \\
\text { last session }\end{array}$ & Content & Homework \\
\hline 9 & $\begin{array}{l}\text { Introductory } \\
\text { three-minute } \\
\text { breathing } \\
\text { space; } \\
\text { discussion of } \\
\text { practice. }\end{array}$ & 1 & $\begin{array}{l}\text { Amy said she only practiced once } \\
\text { over the week because she "couldn't } \\
\text { find the time." Amy and therapist } \\
\text { discussed her feeling that she is not } \\
\text { practicing "correctly." }\end{array}$ & $\begin{array}{l}\text { Continue practicing at } \\
\text { least one sitting } \\
\text { meditation and one } \\
\text { body scan. }\end{array}$ \\
\hline 10 & $\begin{array}{l}\text { Introductory } \\
\text { three-minute } \\
\text { breathing } \\
\text { space; taught } \\
\text { three-minute } \\
\text { breathing } \\
\text { space; informal } \\
\text { practice. }\end{array}$ & $\begin{array}{l}1 \text { (sitting } \\
\text { meditation of } \\
\text { the breath) }\end{array}$ & $\begin{array}{l}\text { Amy said she didn’t like practicing } \\
\text { the body scan because she "never } \\
\text { really knew” what she was } \\
\text { "supposed to be doing.” She and } \\
\text { therapist discussed her reaction to } \\
\text { feeling like she was practicing } \\
\text { wrong. Amy identified driving as a } \\
\text { possible informal mindfulness } \\
\text { activity. }\end{array}$ & $\begin{array}{l}\text { Practice three-minute } \\
\text { breathing space at least } \\
\text { once a day; informal } \\
\text { practice. }\end{array}$ \\
\hline 11 & $\begin{array}{l}\text { Introductory } \\
\text { three-minute } \\
\text { breathing } \\
\text { space; } \\
\text { discussion of } \\
\text { practice. }\end{array}$ & $\begin{array}{l}2 \text { (three- } \\
\text { minute } \\
\text { breathing } \\
\text { space) }\end{array}$ & $\begin{array}{l}\text { Amy said that she "didn't like” the } \\
\text { sitting practices because she never } \\
\text { knew if she was practicing "right." } \\
\text { Amy and therapist discussed Amy’s } \\
\text { avoidance of the feeling that she is } \\
\text { incorrectly practicing and how this } \\
\text { aversive feeling is preventing her } \\
\text { from practicing. }\end{array}$ & $\begin{array}{l}\text { Continue practice } \\
\text { three-minute breathing } \\
\text { space at least once a } \\
\text { day; informal practice. }\end{array}$ \\
\hline 12 & $\begin{array}{l}\text { Introductory } \\
\text { three-minute } \\
\text { breathing } \\
\text { space; sitting } \\
\text { mindful yoga. }\end{array}$ & $\begin{array}{l}2 \text { (three- } \\
\text { minute } \\
\text { breathing } \\
\text { space) }\end{array}$ & $\begin{array}{l}\text { Amy said that she was "unsure" of } \\
\text { the response the therapist was } \\
\text { looking for when he asked her about } \\
\text { her experience during the } \\
\text { introductory meditation. She said } \\
\text { that her mind easily wandered while } \\
\text { practicing, but found the mindful } \\
\text { yoga "easier because it was more } \\
\text { active." }\end{array}$ & $\begin{array}{l}\text { Practice mindful yoga } \\
\text { at least three times. } \\
\text { Informal practice. }\end{array}$ \\
\hline 13 & $\begin{array}{l}\text { Introductory } \\
\text { three-minute } \\
\text { breathing } \\
\text { space; } \\
\text { processing end } \\
\text { of practice } \\
\text { sessions. }\end{array}$ & $\begin{array}{l}4 \text { (mindful } \\
\text { yoga) }\end{array}$ & $\begin{array}{l}\text { Amy said she found the mindful } \\
\text { yoga "very helpful" and noticed her } \\
\text { mind wandering less. She said that } \\
\text { mindfulness has "helped me slow } \\
\text { down and relax." Amy and the } \\
\text { therapist discussed how Amy could } \\
\text { continue practicing, paying attention } \\
\text { to her tendency to avoid practice if } \\
\text { she feels she's practicing incorrectly. }\end{array}$ & \\
\hline
\end{tabular}

